\title{
Pseudomesotheliomatous lung carcinoma: a pathological assessment of selected cases including the work history and presence of biomarkers suggesting it is a cancer caused by asbestos
}

\author{
Samuel P. Hammar ${ }^{1}$ and Ronald F. Dodson ${ }^{2^{*}}$ \\ *Correspondence: ron@ericonsulting.com

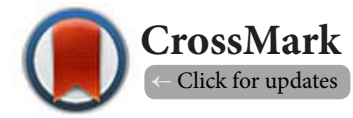 \\ 'Diagnostic Specialties Laboratory, Bremerton, Washington 98310, USA. \\ ${ }^{2}$ Dodson Environmental Consulting, Inc., Tyler, TX, USA.
}

\begin{abstract}
Background: We report a series of 196 cases of pseudomesotheliomatous neoplasms identified in one of our laboratories between 1983 and 2015. We also performed an extensive review of the literature. Most "pseudomesotheliomas" arise in the pleural tissue of the chest cavity and resemble pleural mesotheliomas, macroscopically and histologically, although some metastasize to the pleura from another site or can metastasize to other parts of the body.

Methods: The criteria for inclusion as a pseudomesotheliomatous neoplasm were: 1) presentation of the tumor as a diffuse pleural neoplasm confirmed radiographically, by video-assisted thoracoscopy, by thoracotomy, or at autopsy; 2) lack of a tumor outside of the lung/chest cavity; and 3) the microscopic, histologic, histochemical, immunohistochemical, and/or ultrastructural features of the neoplasm other than a mesothelioma, or a neoplasm other than a mesothelioma that showed histologic, histochemical, immunohistochemical features of a specific neoplasm.

Results: Of the 196 patients in our series, 183 were primary in the lung, 2 were primary in the peritoneum, and 11 were metastatic from another site. One hundred thirty-four (68.3\%) had a known history of exposure to asbestos (130 occupational and 4 bystander/paraoccupational). Six (6) had no history of exposure to asbestos; and in 56 cases, the exposure history was unknown. Of the 196 cases, 109 (55\%) had a history of cigarette smoking, 23 were nonsmokers, and in 64 cases the smoking history was unknown. Of the 196 cases of pseudomesotheliomatous neoplasms arising in the lung/pleura and peritoneum, 134 (68.3\%) had historical exposure to asbestos in the workplace or as a result of paraoccupational and/or bystander exposure; $100(51 \%)$ had radiographic and/or pathologic evidence of pleural plaques or pathologically definable asbestosis; and 56 of 59 cases evaluated for ferruginous bodies and/or asbestos fibers had above background levels in digested lung tissues.
\end{abstract}

Conclusions: We conclude there is a relationship between the development of pseudomesotheliomatous lung cancer and asbestos exposure based on radiological/pathological findings (including tissue burden of ferruginous bodies and/or uncoated asbestos fibers) as correlated with a background history in many individuals within this study.

Keywords: Pseudomesotheliomatous lung cancer, asbestos, cigarette smoke, asbestosis, fiber analysis

\section{Introduction}

The purpose of our article is to report on the clinical and pathologic features of pseudomesotheliomatous lung cancer and to determine if there is a causal relationship between asbestos exposure and/or cigarette smoking. Most cases of pseudomesotheliomatous lung cancer are diagnosed clinically 
Hammar et al. Pathology Discovery 2015,

as mesotheliomas, but when the tissue is further evaluated by histochemistry, immunohistochemistry, and/or electron microscopy, the pathologic findings indicate these tumors are not mesotheliomas but are, in fact, primary lung cancers or metastatic cancers growing in a distribution that macroscopically resembles mesothelioma. The criteria for including a case as a pseudomesotheliomatous neoplasm in our study were: 1) presentation of the tumor as a diffuse pleural neoplasm confirmed radiographically, by video-assisted thoracoscopy, by thoracotomy, or by autopsy; 2) lack of a tumor outside of the lung or chest cavity; and 3) the microscopic, histologic, histochemical, immunohistochemical, and/or ultrastructural features of the neoplasm other than a mesothelioma, or a neoplasm other than a mesothelioma that showed histologic, histochemical, immunohistochemical features of a specific neoplasm. Some pseudomesotheliomatous lung cancers represented metastatic cancers from a site outside of the chest that grew in a diffuse pleural distribution macroscopically mimicking a diffuse pleural mesothelioma. We also performed an extensive review of the literature concerning pseudomesotheliomatous lung cancers, which are summarized in Table 1 [1-40].

\section{Materials and methods}

Tissue samples were evaluated in 196 individuals who were diagnosed as having pseudomesotheliomatous neoplasms (194 pleural; 2 peritoneal). These neoplasms were received during the normal course of business by Diagnostic Specialties Laboratory, Inc., P.S., Bremerton, Washington (laboratory of Samuel P. Hammar, M.D.) between 1983 and 2015. These materials were considered discarded at the time of our study. No name identifiers were used. Of the 196 cases, thirty (30) were medical consultation cases; fourteen (14) were surgical cases from Harrison Medical Center, Bremerton, Washington; and 152 were medico-legal cases which were sent to one of our laboratory's (SPH) for possible asbestos-related litigation. Most were subtypes of primary pulmonary adenocarcinoma and other non-mesothelial cancers. When indicated, histochemical studies were performed on $4 \mu \mathrm{m}$ thick sections for Periodic acid-Schiff (PAS), PAS-diastase, mucicarmine, and Alcian blue with and without hyaluronidase according to standard techniques. Immunohistochemical studies were performed on paraffin embedded tissue, if available, according to standard techniques using the Ventana Bench Mark System ${ }^{\circledast}$. Positive and negative controls were run for each test performed. Because these cases involved diffuse malignant pleural mesothelioma in the differential diagnosis, a combination of positive and negative markers were used for differentiating epithelial mesothelioma from primary pulmonary adenocarcinoma. The antigens most commonly used as positive markers for epithelial mesothelioma (negative markers for primary pulmonary adenocarcinoma) were calretinin, cytokeratin $5 / 6$, cytokeratin 7 , mesothelin, D2-40 (podoplanin), and HBME-1. The most commonly used positive markers for primary pulmonary adenocarcinoma (negative markers for epithelioid mesothelioma) were carcinoembryonic antigen (CEA), LeuM1 (CD15), thyroid transcription factor-1 (TTF-1), B72.3 and BerEP4. In the event that ultrastructural evaluation was required to aid in the diagnosis, tissue specimens were fixed in Trump's fixative and in some instances neutral buffered formalin. In rare instances, tissue was removed from paraffin blocks and processed for ultrastructural evaluation.

In cases where formalin-fixed autopsy tissue was available, 5-gram samples of peripheral lung tissue were cut into small pieces and completely digested in commercial bleach at Diagnostic Specialties Laboratory in Bremerton, Washington. After complete digestion, the bleach was carefully decanted and the sediment at the bottom of the container was carefully extracted with equal volumes of chloroform and $50 \%$ ethyl alcohol. This solution was transferred to a test tube, shaken vigorously, and centrifuged at 1200 revolutions per minute (rpm) for ten minutes. After removal of as much carbonaceous material as possible, the solution was re-centrifuged and the sediment at the bottom of the test tube was extracted in $95 \%$ alcohol and passed through a Millipore filter of 0.5 micrometer diameter pore size. Ferruginous bodies (morphologically consistent with the appearance of asbestos-cored ferruginous bodies) on the filter were then counted. In our laboratories (SPH, RFD), persons in the general population may have between 0-20 asbestos bodies per gram of wet lung tissue, which we consider to be background levels [41].

Formalin-fixed lung tissue from 20 cases was submitted to the Tyler laboratory (Ronald F. Dodson's laboratory) and prepared for evaluation via a digestion procedure using a modified bleach procedure [42]. The extensive findings from this evaluation were published in a companion manuscript [43]. A synopsis of the methodology used was: "Dry weights were calculated based on a dry/wet ratio obtained for each digestion pool. All reagents were pre-filtered through 0.2 $\mu \mathrm{m}$ pored polycarbonate filter prior to use in the digestion procedure. Control blanks of filters and solution blanks were prepared and evaluated to provide quality assurance within the laboratory. Aliquots of the digestate from each sample were collected on $0.22 \mu \mathrm{m}$ pored mixed cellulose ester filter for quantitation of ferruginous body content of the tissue samples, while additional aliquots were collected on $0.2 \mu \mathrm{m}$ pored polycarbonate filters and prepared for evaluation by Analytical Transmission Electron Microscopy (ATEM) for the determination of uncoated asbestos fibers and assessment of core materials of any ferruginous bodies found in the areas evaluated. The preparation of the mixed cellulose filters used for determination of ferruginous body content of the tissue consisted of mounting a wedge of each filter on a glass slide, exposing the filter to acetone vapor (making the substrate transparent) and evaluation of the 'cleared' surface at 100x with magnification increased to $400 x$ via a light microscope if additional morphological clarification was desired. Structures conforming to the definition of a ferruginous body as seen by light microscopy 
Hammar et al. Pathology Discovery 2015,

Table 1. Summary of peer-reviewed journal articles of pseudomesotheliomatous neoplasms.

\begin{tabular}{|c|c|c|c|c|c|c|}
\hline References & $\begin{array}{l}\text { Age } \\
\text { Range }\end{array}$ & Sex & Histologic Type & Occupation & $\begin{array}{l}\text { Asbestos } \\
\text { exposure? }\end{array}$ & Tobacco use? \\
\hline$[1]$ & $43-68$ & $\begin{array}{l}\mathrm{M}(3) \\
\mathrm{F}(2)\end{array}$ & $\begin{array}{l}\text { Adenocarcinoma ( } 3) \text {; } \\
\text { Small cell lung cancer (2) }\end{array}$ & Unknown (5) & Unknown (5) & Unknown (5) \\
\hline [2] & $49-76$ & $\mathrm{M}(6)$ & $\begin{array}{l}\text { Bronchiolar adenocarcinoma (5); } \\
\text { Adenocarcinoma, poorly differentiated (1) }\end{array}$ & $\begin{array}{l}\text { Shipyard worker WWII (1) } \\
\text { Unknown (5) }\end{array}$ & $\begin{array}{l}\text { Yes (1) } \\
\text { Unknown (5) }\end{array}$ & $\begin{array}{l}\text { Yes (5) } \\
\text { Unknown (1) }\end{array}$ \\
\hline [3] & 55 & $\mathrm{M}(1)$ & Adenocarcinoma, tubulodesmoplastic type & Unknown & No & Yes \\
\hline$[4]$ & 65 & $\mathrm{M}(1)$ & $\begin{array}{l}\text { Adenocarcinoma, tubulodesmoplastic type; } \\
\text { mucin-producing }\end{array}$ & Unknown & Unknown & Unknown \\
\hline$[5]$ & $59-80$ & $\mathrm{M}(2)$ & $\begin{array}{l}\text { Bronchiolar carcinoma with metastasis to } \\
\text { brain, adrenal glands, and liver (1); } \\
\text { Adenocarcinoma, mucinous papillary (1) }\end{array}$ & Unknown (2) & Unknown (2) & $\begin{array}{l}\text { Yes (1) } \\
\text { Unknown (1) }\end{array}$ \\
\hline$[6]$ & 56 & $\mathrm{M}(1)$ & Adenocarcinoma, poorly differentiated & Unknown & No & Yes \\
\hline [7] & 69 & $\mathrm{M}(1)$ & Bronchoalveolar carcinoma & Blacksmith in an iron foundry & Yes & Yes \\
\hline$[8]$ & $70-85$ & $\begin{array}{l}\mathrm{M}(2) \\
\mathrm{F}(1)\end{array}$ & $\begin{array}{l}\text { Adenocarcinoma, tubulodesmoplastic type } \\
\text { (2) } \\
\text { Adenocarcinoma, tubulopapillary (1) }\end{array}$ & Unknown (3) & $\begin{array}{l}\text { Probable (1) } \\
\text { Possible (1) } \\
\text { No (1) }\end{array}$ & $\begin{array}{l}\text { Yes (2) } \\
\text { Unknown (1) }\end{array}$ \\
\hline [9] & 70 & $\mathrm{M}(1)$ & $\begin{array}{l}\text { Laryngeal carcinoma metastatic to the } \\
\text { pleura, poorly differentiated squamous cell }\end{array}$ & Shipyard electrician & Yes & Yes \\
\hline$[10]$ & Mean, 61 & $\begin{array}{l}\text { M (13) } \\
\mathrm{F}(2)\end{array}$ & Adenocarcinoma, mucin producing (15) & Not stated & Yes (3) & Yes $(8)$ \\
\hline$[11]$ & Not stated & Not stated & $\begin{array}{l}\text { Adenocarcinoma (23); } \\
\text { Squamous carcinoma (2); } \\
\text { Large cell undifferentiated carcinoma (1); } \\
\text { Adenosquamous carcinoma (1) }\end{array}$ & Not stated & Not stated & Not stated \\
\hline$[12]$ & $\begin{array}{l}68 \pm 9 \\
\text { years }\end{array}$ & Not stated & $\begin{array}{l}\text { Primary pulmonary adenocarcinoma (63); } \\
\text { Primary squamous cell carcinomas of lung } \\
\text { (2); } \\
\text { Extrapulmonary tumors (7)-metastatic } \\
\text { from kidney, ureter, urinary bladder, } \\
\text { appendix vermiformis, thymoma, and } \\
\text { cystosarcoma phyllodes of the contralateral } \\
\text { mamma }\end{array}$ & Unknown (72) & Yes (2) & $\begin{array}{l}\text { Average } \\
\text { nonsmokers } \\
44 \%\end{array}$ \\
\hline$[13]$ & 32 & $\mathrm{M}(1)$ & Large cell carcinoma & Unknown & Unknown & Unknown \\
\hline$[14]$ & $51-64$ & $\mathrm{M}(4)$ & Small cell carcinoma (4) & $\begin{array}{l}\text { Foundry worker (1) } \\
\text { Unknown (3) }\end{array}$ & Unknown (4) & Yes $(4)$ \\
\hline$[15]$ & $34-85$ & $\begin{array}{l}\mathrm{M}(12) \\
\mathrm{F}(2)\end{array}$ & $\begin{array}{l}\text { Epithelioid angiosarcoma (7); } \\
\text { Epithelioid hemangioendothelioma (7) }\end{array}$ & Unknown (14) & $\begin{array}{l}\text { Yes (1) } \\
\text { Unknown (13) }\end{array}$ & Unknown (14) \\
\hline$[16]$ & $\begin{array}{l}31-78 \\
\text { median } \\
\text { age } 63\end{array}$ & $\begin{array}{l}\text { M (24) } \\
\text { F (5) }\end{array}$ & Adenocarcinoma (29) & Unknown (29) & $\begin{array}{l}\text { Possible/definite } \\
\text { (6) }\end{array}$ & Yes (13) \\
\hline$[17]$ & $63-67$ & $\mathrm{M}(3)$ & $\begin{array}{l}\text { Left pleural epithelioid neoplasm, papillary } \\
\text { and alveolar cell morphology (1); } \\
\text { Pleural tumor, probable undifferentiated } \\
\text { adenocarcinoma (1); } \\
\text { Pleural tumor that penetrated peritoneal } \\
\text { cavity, biphasic with desmoplastic reaction } \\
\text { with epithelioid cells producing mucus (1) }\end{array}$ & Unknown (3) & $\begin{array}{l}\text { Yes }(1) \\
\text { No }(2)\end{array}$ & $\begin{array}{l}\text { Yes (2) } \\
\text { Remote (1) }\end{array}$ \\
\hline$[18]$ & $45-66$ & $\begin{array}{l}\mathrm{M}(4) \\
\mathrm{F}(1)\end{array}$ & Angiosarcoma, primary pleural (5) & Unknown (5) & Unknown (5) & Unknown (5) \\
\hline [19] & $33-73$ & $\mathrm{M}(3)$ & $\begin{array}{l}\text { Epithelioid hemangioendothelioma, } \\
\text { primary pleural (3) }\end{array}$ & $\begin{array}{l}\text { Laborer (1) } \\
\text { Shipyard joiner (1) } \\
\text { Shipyard welder (1) }\end{array}$ & Yes (3) & Unknown (3) \\
\hline [20] & 75 & $\mathrm{M}(1)$ & Adenocarcinoma, primary pulmonary & Biology teacher & Unknown & Unknown \\
\hline$[21]$ & 73 & M (2) & Atypical carcinoid tumor (2) & $\begin{array}{l}\text { Power station worker (1) } \\
\text { Shipyard worker (1) }\end{array}$ & $\begin{array}{l}\text { Yes (1) } \\
\text { Likely (1) }\end{array}$ & Yes $(2)$ \\
\hline$[22]$ & $14-20$ & $\mathrm{M}(2)$ & $\begin{array}{l}\text { Primary pseudomesotheliomatous } \\
\text { yolk-sac tumor (1); } \\
\text { Embryonal carcinoma with yolk-sac tumor } \\
\text { of the lung/mixed germ cell tumor (1) }\end{array}$ & Unknown (2) & Unknown (2) & Unknown (2) \\
\hline [23] & 74 & $\mathrm{M}(1)$ & Pseudomesotheliomatous angiosarcoma & Unknown & No & No \\
\hline
\end{tabular}


Hammar et al. Pathology Discovery 2015,

http://www.hoajonline.com/journals/pdf/2052-7896-3-6.pdf

Continuations of Table 1.

\begin{tabular}{|c|c|c|c|c|c|c|}
\hline References & $\begin{array}{l}\text { Age } \\
\text { Range }\end{array}$ & Sex & Histologic Type & Occupation & $\begin{array}{l}\text { Asbestos } \\
\text { exposure? }\end{array}$ & Tobacco use? \\
\hline$[24]$ & $\begin{array}{l}33-77 ; \\
\text { median } \\
\text { age } 68 \\
\text { years }\end{array}$ & $\begin{array}{l}\mathrm{M}(50) \\
\mathrm{F}(3)\end{array}$ & $\begin{array}{l}\text { Primary lung tumors }=47 \\
\text { Adenocarcinoma (34) } \\
\text { Pleomorphic carcinoma (5) } \\
\text { Squamous carcinoma (4) } \\
\text { Small cell carcinoma (2) } \\
\text { Basaloid carcinoma (1) } \\
\text { Carcinosarcoma (1) } \\
\text { Metastatic carcinomas =6 } \\
\text { Transitional cell (2) } \\
\text { Pancreatic (1) } \\
\text { Renal cell (1) } \\
\text { Prostatic (1) } \\
\text { Squamous carcinoma parotid (1) }\end{array}$ & Unknown & Yes - $40(76 \%)$ & Yes $-46(87 \%)$ \\
\hline$[25]$ & 53 & $\mathrm{M}(1)$ & Adenocarcinoma of lung & Unknown & Unknown & Unknown \\
\hline$[26]$ & 35 & $\mathrm{M}(1)$ & Primary signet ring cell carcinoma of lung & Construction laborer & Probable & Yes \\
\hline$[27]$ & $58-73$ & $\begin{array}{l}\text { M (4) } \\
F(3)\end{array}$ & $\begin{array}{l}\text { Adenocarcinoma, poorly differentiated (5); } \\
\text { Large cell adenocarcinoma (1); } \\
\text { Small cell carcinoma (1) }\end{array}$ & Unknown (7) & Unknown (7) & Unknown (7) \\
\hline$[28]$ & 68 & $M(1)$ & Multiple myeloma & Unknown & $\begin{array}{l}\text { Yes - } \\
\text { environmental }\end{array}$ & Unknown \\
\hline$[29]$ & 64 & $\mathrm{~F}(1)$ & Melanoma metastatic to pleura & Unknown & No & Yes \\
\hline$[30]$ & 55 & $\mathrm{M}(1)$ & $\begin{array}{l}\text { Pleomorphic carcinoma with } \\
\text { adenocarcinoma component }\end{array}$ & Unknown & No & Yes \\
\hline$[31]$ & 45 & $\mathrm{M}(1)$ & Erdheim-Chester disease & Construction worker & Probable & No \\
\hline$[32]$ & 78 & M (1) & $\begin{array}{l}\text { Concomitant adenocarcinoma of lung, } \\
\text { gastric cancer, and esophageal cancer }\end{array}$ & Unknown & No & Yes \\
\hline$[33]$ & $53-66$ & $\begin{array}{l}\mathrm{M}(3) \\
\mathrm{F}(1)\end{array}$ & Adenocarcinoma of lung (4) & Unknown (4) & $\begin{array}{l}\text { Yes (1) } \\
\text { Unknown (3) }\end{array}$ & Yes (4) \\
\hline$[34]$ & 72 & $M(1)$ & Adenocarcinoma of lung & Unknown & Unknown & Unknown \\
\hline$[35]$ & $45-80$ & $\begin{array}{l}M(1) \\
F(1)\end{array}$ & Plasma cell myeloma/plasmacytoma (2) & $\begin{array}{l}\text { Shipyard worker (1) } \\
\text { Unknown (1) }\end{array}$ & $\begin{array}{l}\text { Yes (1) with } \\
122,000 \text { asbestos } \\
\text { bodies per gram } \\
\text { dry lung tissue; } \\
\text { Unknown (1) }\end{array}$ & Unknown (2) \\
\hline$[36]$ & 37 & $\mathrm{M}(1)$ & $\begin{array}{l}\text { Angiosarcoma of the spleen with metastases } \\
\text { to pleura and peritoneum }\end{array}$ & Unknown & No & Unknown \\
\hline$[37]$ & 74 & $M(1)$ & $\begin{array}{l}\text { Adenocarcinoma of lung, } \\
\text { poorly-differentiated }\end{array}$ & Unknown & No known & Yes \\
\hline$[38]$ & 65 & $M(1)$ & Merkel cell carcinoma & $\begin{array}{l}\text { Underground coal miner in } \\
\text { South Wales for } 30 \text { years }\end{array}$ & No & Not stated \\
\hline$[39]$ & $76-80$ & $M(2)$ & $\begin{array}{l}\text { Adenocarcinoma, primary pulmonary (1); } \\
\text { Squamous cell carcinoma of lung (1) }\end{array}$ & Unknown (2) & No known (2) & Yes (2) \\
\hline$[40]$ & 53 & $M(1)$ & Pulmonary mucinous cystadenocarcinoma & Unknown & Yes & Yes \\
\hline
\end{tabular}

Key: M, male; F, female; Probable-cases in which there was no statement as to whether or not the patient was exposed to asbestos, however, based on their employment history, the likelihood exists.

were counted. The definition of such a ferruginous body included elongated/transparent central core and a rust colored beaded surface. The polycarbonate filters were prepared for ATEM analysis by a direct method involving collection of the digestate on the filter surface followed by carbon coating of the dried filter. The carbon coated filter was cut into strips and mounted on 100 mesh copper grids. A modified Jaffe-Wick method [44] was used to remove the filter matrix, leaving the carbon film containing the entrapped fibers, ferruginous bodies, and other particulates. Random areas on the grids were evaluated at $16,000 x$ for uncoated fibers in a JEOL $100 C X$ transmission electron microscope which was interfaced with an EDAX DX Prime X-ray analyzer. An additional scan of other areas on the grids was conducted at 1,600x for the presence of additional ferruginous bodies. A fiber as defined in the present study consisted of an elongated entity $\geq 0.5 \mu \mathrm{m}$ with parallel sides for a majority of its length and an aspect ratio of greater than 5:1. Uncoated fibers as well as the core material of ferruginous bodies were analyzed as to elemental composition by X-ray energy dispersive spectrometry 
Hammar et al. Pathology Discovery 2015,

http://www.hoajonline.com/journals/pdf/2052-7896-3-6.pdf

doi: 10.7243/2052-7896-3-6

(XEDS) and for crystalline structure by selected area electron diffraction (SAED)".

\section{Results}

Approximately $90 \%$ of the cases received for evaluation by one of us (SPH) were thought clinically to have diffuse malignant pleural mesothelioma and two were thought to be peritoneal mesotheliomas. The most common clinical symptom was dyspnea on exertion. Other common symptoms included chest pain/discomfort, cough, weight loss, and fatigue. Less frequent symptoms included abdominal pain/ distention, back pain, shoulder pain, fever, weakness, and anorexia. Many patients exhibited more than one symptom. The most frequent radiographic changes included pleural thickening/nodularity and a unilateral pleural effusion that often re-accumulated rapidly. Following pathologic evaluation by one of us (SPH), one-hundred eighty three (183) of the 196 cases were determined to be primary in the lung; 2 were primary in the peritoneum; and 11 were metastatic to the lung from another site (kidney-4; skin-3; mouth/tongue-2; Mullerian origin-1; and possibly larynx-1). Of the 196 cases, 173 were males, 21 were females, and in 2 cases the sex was unknown. The age-range was between 23 and 96 years with a mean age of 62.89 years.

A summary of the 196 cases evaluated in our laboratory (Diagnostic Specialties Laboratory, Inc. P.S.) is shown in Table 2. The various histologic types identified in our cases are shown in Table 3. The macroscopic and ultrastructural features of a pseudomesotheliomatous pulmonary adenocarcinoma are shown in Figures 1-5.

One hundred thirty-four patients (68.3\%) had a known history of exposure to asbestos (130 occupational and 4 bystander/paraoccupational); six (6) had no history of exposure to asbestos; and in 56 cases, the exposure history was unknown. It should be stated that in 6 cases where the occupational history was known (painter; welder in a steel mill; digester cooker in a pulp/paper mill; shipyard worker-2 cases; and crew boat captain/welder/fisherman) but the asbestos exposure history was stated to be "unknown," one has to wonder if there was possible exposure to asbestos based on their occupation/job title. Of the 62 cases where there was no known history or an unknown history of asbestos exposure, 25 (40.3\%) had either pathologic or radiographic markers of asbestos exposure, e.g., pleural plaques, asbestosis, and/or ferruginous bodies/ asbestos fibers in lung tissue. Pleural plaque characteristic of plaque caused by asbestos was identified in 89 cases (56 pathologically, 12 radiographically, and 21 both pathologically and radiographically). Forty-six (46) cases had pathologically definable asbestosis (CAP-NIOSH 1982). Radiographic asbestosis was identified in 4 cases and 1 had probable asbestosis.

A total of 59 cases were evaluated in the laboratory of one of us (Samuel P. Hammar, M.D.) for ferruginous bodies that were morphologically characteristic of asbestos bodies ( 5 by iron stained sections and 54 using quantitative asbestos digestion

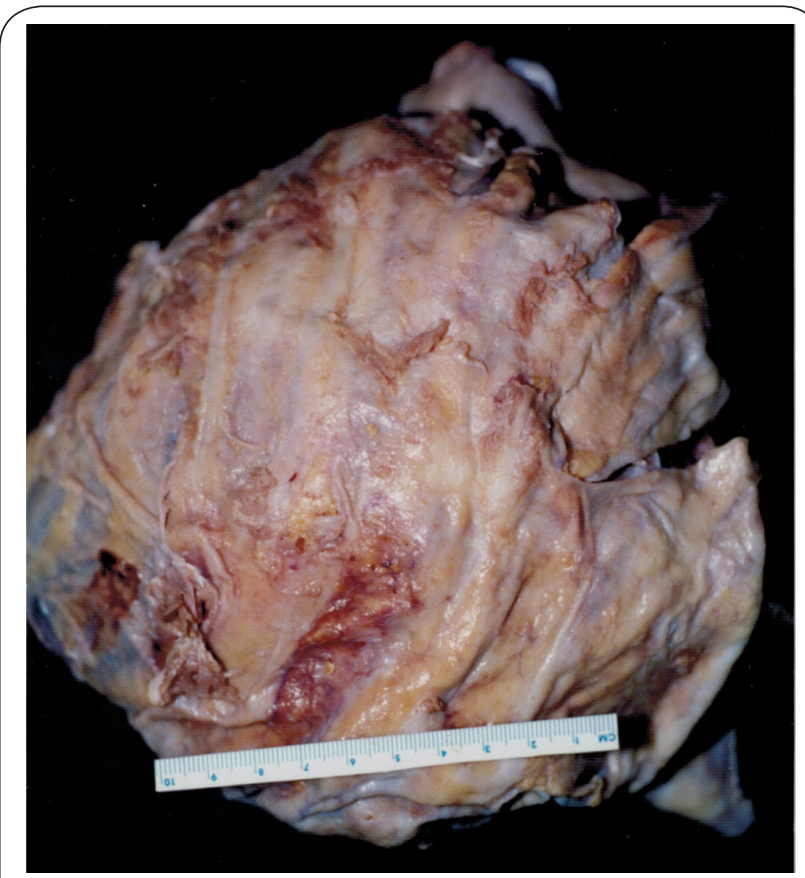

Figure 1. This tumor has the macroscopic features of a pleural mesothelioma, being encased by a rind of tumor that when examined microscopically had features of a primary pulmonary adenocarcinoma.

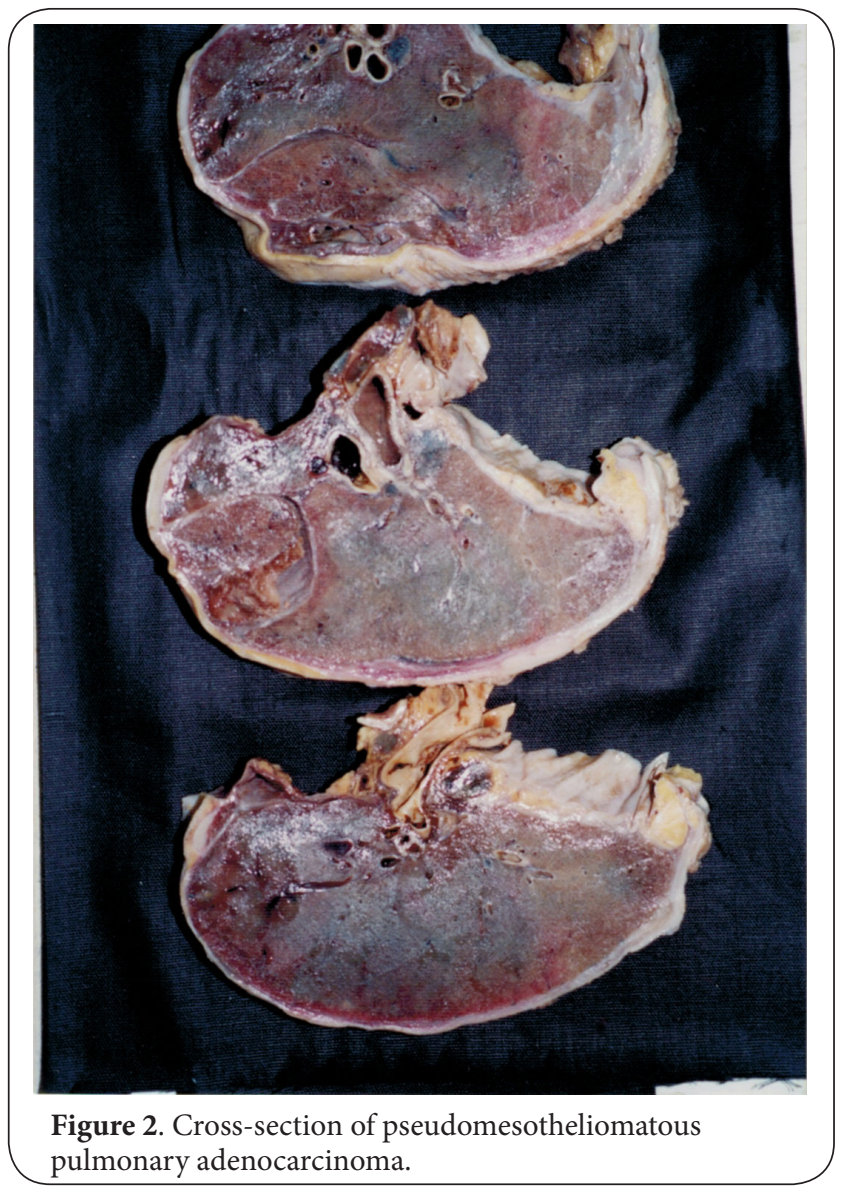




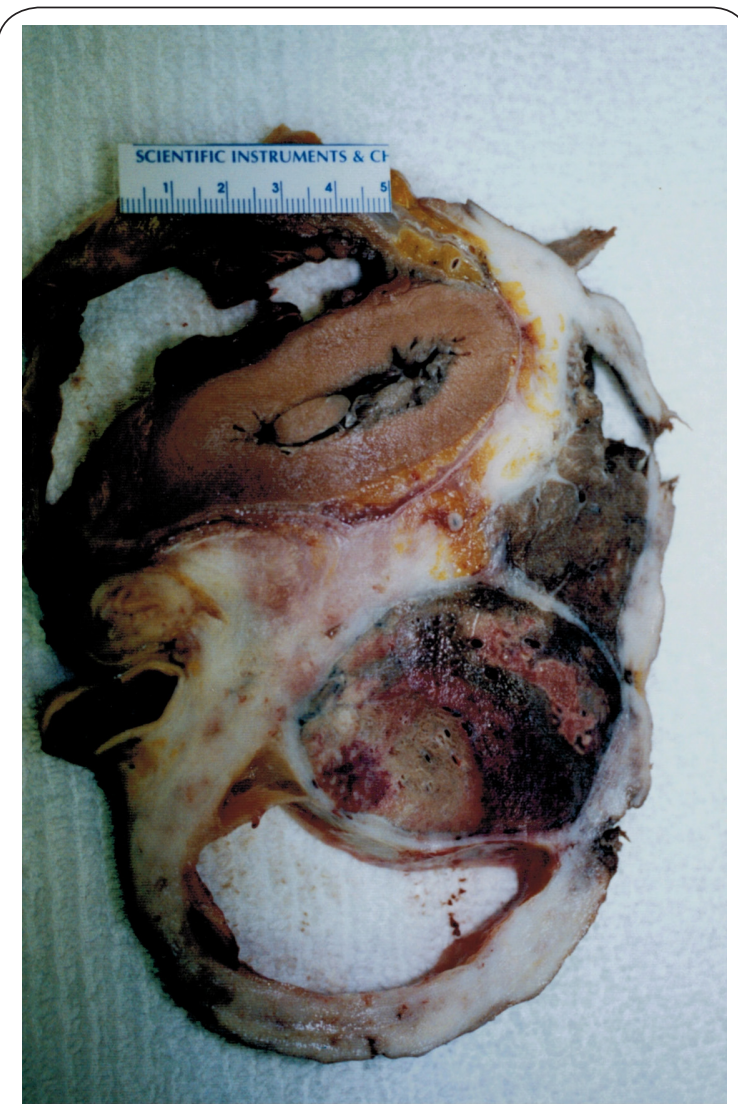

Figure 3. This pseudomesotheliomatous adenocarcinoma surrounds the heart and lung.

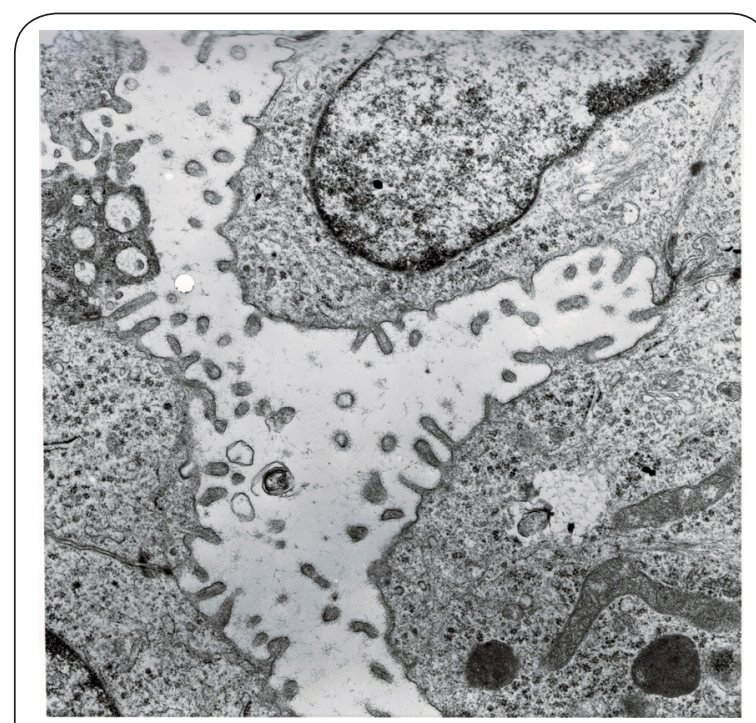

Figure 4. Ultrastructural evaluation of this pseudomesotheliomatous adenocarcinoma of lung shows short microvilli and a fuzzy glycocalyx; whereas, in a pleural epithelioid mesothelioma, the microvilli would be long and sinuous and not covered by glycocalyx (see Figure 5).

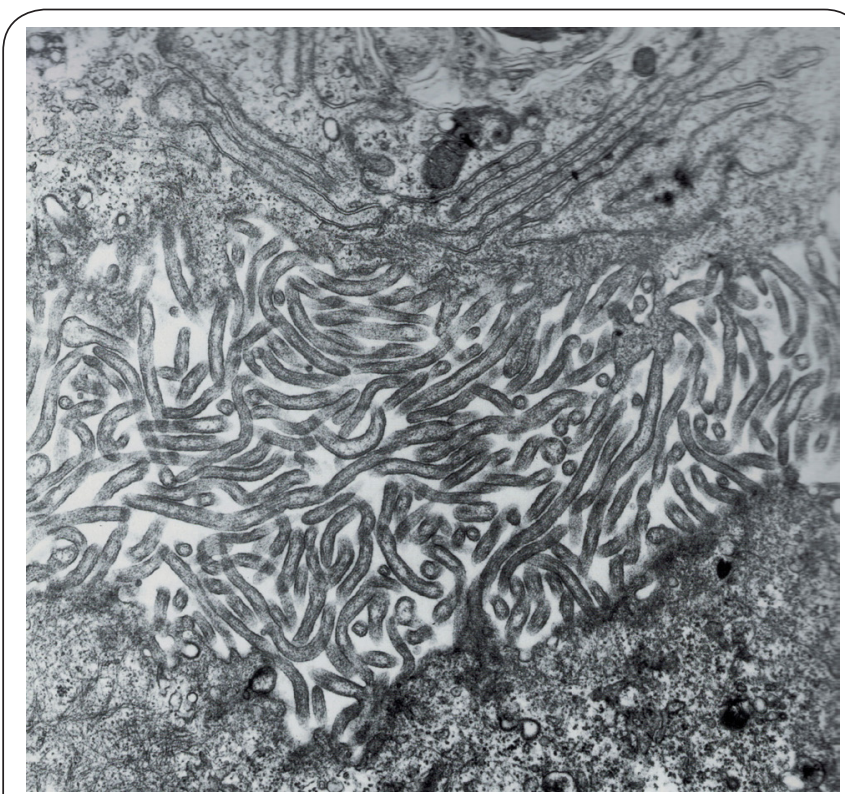

Figure 5. Ultrastructural evaluation of a pleural epithelioid mesothelioma showing long, sinuous microvilli that are not covered by glycocalyx.

analysis). In addition, asbestos fiber analysis was performed in Dr. Ronald F. Dodson's laboratory on 24 cases. These cases were evaluated using standardized techniques as described in the Materials and Methods section. Results are shown in Table 4. By quantitative asbestos digestion analysis, 47 of 54 cases had above background levels (over 20 ferruginous bodies per gram wet lung tissue) in at least one or more lobes of lung. It should be noted that in 4 cases where the results fell below background levels ( 20 or less ferruginous bodies per gram wet lung tissue in our laboratory), when fiber analysis was performed, those same four cases showed background levels at the upper limits of levels found in general populations (see cases \#160,163,164, and 165) and often the burden in one lung would greatly exceed the average found in the general studies conducted by one of us (RFD). This illustrates that asbestos fibers are not evenly distributed in the lungs. Of the 20 cases studied by analytical transmission electron microscopy (ATEM) in the laboratory of Ronald F. Dodson, Ph.D., for ferruginous bodies and uncoated fibers [43], 19 cases contained tissue burden of asbestos in at least one of the lung samples in appreciable excess of the average background levels found in the general population studies $[41,45]$. The numbers of asbestos bodies identified in the right lung versus the left lung also varied, which further illustrates that asbestos fibers are not evenly distributed in the lungs. Of the 196 cases, 109 (55.6\%) were cigarette smokers, 23 (11.7\%) were nonsmokers, and in 64 cases the smoking history was unknown. Of the 109 patients who were known smokers, 61 had a greater than 20-pack year history of cigarette smoking. 
Hammar et al. Pathology Discovery 2015,

http://www.hoajonline.com/journals/pdf/2052-7896-3-6.pdf

doi: 10.7243/2052-7896-3-6

Table 2. Case summary of 196 cases of pseudomesotheliomatous neoplasms.

\begin{tabular}{|c|c|c|c|c|c|c|c|c|c|c|}
\hline ID\# & Age & Sex & $\begin{array}{l}\text { Smoking } \\
\text { History }\end{array}$ & $\begin{array}{l}\text { Occupational } \\
\text { History }\end{array}$ & $\begin{array}{l}\text { Asbestos } \\
\text { exposure? }\end{array}$ & $\begin{array}{l}\text { Pleural } \\
\text { plaques }\end{array}$ & $\begin{array}{l}\text { Asbestosis (1982 } \\
\text { CAP-NIOSH) }\end{array}$ & $\begin{array}{l}\text { Ferruginous } \\
\text { bodies OR } \\
\text { Asbestos fibers } \\
\text { (Refer to Table 4) }\end{array}$ & $\begin{array}{l}\text { Pathologic } \\
\text { diagnosis }\end{array}$ & Survival \\
\hline 110 & 63 & M & $\begin{array}{l}40 \text {-pack } \\
\text { years }\end{array}$ & $\begin{array}{l}\text { Automotive } \\
\text { mechanic }\end{array}$ & Yes & No & No & No FB detected & $\begin{array}{l}\text { Adenocarcinoma } \\
\text { of lung, acinar } \\
\text { and signet ring } \\
\text { morphology }\end{array}$ & 17 months \\
\hline 001 & 59 & $\mathrm{M}$ & Unknown & Shipyard worker & Unknown & $\mathrm{P}$ & No & -- & $\begin{array}{l}\text { Adenocarcinoma } \\
\text { of lung, acinar } \\
\text { type }\end{array}$ & Unknown \\
\hline $\begin{array}{l}150 / \\
\text { FA05 }\end{array}$ & 76 & M & $\begin{array}{l}1 \text { pack } \\
\text { per day, } \\
\text { \# of years } \\
\text { unknown }\end{array}$ & $\begin{array}{l}\text { Built kitchen } \\
\text { equipment }\end{array}$ & Yes & $\mathrm{P}$ & $\begin{array}{l}\mathrm{P} \\
\text { Grade 3-4 }\end{array}$ & $\begin{array}{l}\mathrm{FB} \text { and } \mathrm{AF} \text { above } \\
\text { background }\end{array}$ & $\begin{array}{l}\text { Adenocarcinoma } \\
\text { of lung, acinar } \\
\text { type }\end{array}$ & 1 month \\
\hline $\begin{array}{l}159 / \\
\text { FA14 }\end{array}$ & 59 & M & $\begin{array}{l}27 \text { to } 80- \\
\text { pack years }\end{array}$ & $\begin{array}{l}\text { Shipyard } \\
\text { sandblaster \& } \\
\text { painter (13 years); } \\
\text { head hooker and } \\
\text { furnace manager } \\
\text { at a steel plant ( } 18 \\
\text { years); laborer }\end{array}$ & Yes & $\mathrm{P}$ & $\mathrm{R}$ & $\begin{array}{l}\mathrm{FB} \text { and } \mathrm{AF} \text { above } \\
\text { background }\end{array}$ & $\begin{array}{l}\text { Adenocarcinoma } \\
\text { of lung, acinar } \\
\text { type }\end{array}$ & 6 months \\
\hline 003 & 67 & M & $\begin{array}{l}\text { Yes-amount } \\
\text { not specified }\end{array}$ & Millwright & Yes & No & No & $\begin{array}{l}\text { FB above } \\
\text { background }\end{array}$ & $\begin{array}{l}\text { Adenocarcinoma } \\
\text { of lung, } \\
\text { anaplastic large } \\
\text { cell } \\
\text { undifferentiated }\end{array}$ & 6 months \\
\hline $\begin{array}{l}166 / \\
\text { U01 }\end{array}$ & 96 & $\mathrm{M}$ & Unknown & $\begin{array}{l}\text { Boilermaker in } \\
\text { shipyards during } \\
1940 \text { s }\end{array}$ & Yes & $\mathrm{P}$ & $\begin{array}{l}\mathrm{P} \\
\text { Grade } 4\end{array}$ & $\begin{array}{l}\text { FB above } \\
\text { background }\end{array}$ & $\begin{array}{l}\text { Adenocarcinoma } \\
\text { of lung, biphasic } \\
\text { type }\end{array}$ & 3 months \\
\hline $\begin{array}{l}146 / \\
\text { FA01 }\end{array}$ & 70 & M & $\begin{array}{l}30 \text {-pack } \\
\text { years }\end{array}$ & $\begin{array}{l}\text { Insulator helper } \\
\text { ( } 5 \text { years) }\end{array}$ & Yes & $\mathrm{P}$ & $\begin{array}{l}\mathrm{P} \\
\text { Grade } 4\end{array}$ & $\begin{array}{l}\mathrm{FB} \text { and } \mathrm{AF} \text { above } \\
\text { background }\end{array}$ & $\begin{array}{l}\text { Adenocarcinoma } \\
\text { of lung, biphasic } \\
\text { type }\end{array}$ & 8 months \\
\hline $\begin{array}{l}151 / \\
\text { FA06 }\end{array}$ & 43 & M & $\begin{array}{l}5+\text { pack } \\
\text { years }\end{array}$ & $\begin{array}{l}\text { Batchmaker/ } \\
\text { mixer, hod carrier, } \\
\text { pipelayer, laborer, } \\
\text { maintenance man }\end{array}$ & Yes & No & No & $\begin{array}{l}\mathrm{FB} \text { and } \mathrm{AF} \text { above } \\
\text { background }\end{array}$ & $\begin{array}{l}\text { Adenocarcinoma } \\
\text { of lung, } \\
\text { epithelioid and } \\
\text { rhabdoid type; } \\
\text { metastases to } \\
\text { liver and lymph } \\
\text { nodes }\end{array}$ & $<1$ year \\
\hline 112 & 83 & $\mathrm{~F}$ & $\begin{array}{l}3 \text { to } 6 \text {-pack } \\
\text { years }\end{array}$ & $\begin{array}{l}\text { Husband worked } \\
\text { as a contractor } \\
\text { and laborer at } \\
\text { shipyards and } \\
\text { refineries }\end{array}$ & $\begin{array}{l}\text { Para- } \\
\text { occupational }\end{array}$ & No & No & -- & $\begin{array}{l}\text { Adenocarcinoma } \\
\text { of lung, glandular } \\
\text { differentiation }\end{array}$ & 8 months \\
\hline 082 & 79 & M & Unknown & Unknown & Unknown & No & No & -- & $\begin{array}{l}\text { Adenocarcinoma } \\
\text { of lung, glandular } \\
\text { differentiation }\end{array}$ & Unknown \\
\hline 076 & 65 & $\mathrm{U}$ & Unknown & Unknown & Unknown & No & No & -- & $\begin{array}{l}\text { Adenocarcinoma } \\
\text { of lung, glandular } \\
\text { differentiation }\end{array}$ & Unknown \\
\hline 048 & 70 & M & No & $\begin{array}{l}\text { Sheet metal } \\
\text { worker }\end{array}$ & Yes & $\mathrm{P}$ & No & -- & $\begin{array}{l}\text { Adenocarcinoma } \\
\text { of lung, glandular } \\
\text { differentiation }\end{array}$ & 6 months \\
\hline 068 & 73 & M & $\begin{array}{l}25 \text { to } 35- \\
\text { pack years }\end{array}$ & $\begin{array}{l}\text { Carpenter } \\
\text { (industrial) }\end{array}$ & Yes & $\mathrm{P}, \mathrm{R}$ & $\begin{array}{l}\mathrm{P} \\
\text { Grade } 4\end{array}$ & $\begin{array}{l}\text { Iron stains: } 01 \\
\text { ferruginous body } \\
\text { characteristic of } \\
\text { an asbestos body }\end{array}$ & $\begin{array}{l}\text { Adenocarcinoma } \\
\text { of lung, glandular } \\
\text { differentiation }\end{array}$ & 12 months \\
\hline 051 & 69 & M & No & $\begin{array}{l}\text { Laborer, welder, } \\
\text { coal miner, } \\
\text { automobile } \\
\text { mechanic }\end{array}$ & Yes & No & No & & $\begin{array}{l}\text { Adenocarcinoma } \\
\text { of lung, glandular } \\
\text { differentiation; } \\
\text { metastasis to } \\
\text { abdominal cavity }\end{array}$ & 4 months \\
\hline
\end{tabular}


Hammar et al. Pathology Discovery 2015,

http://www.hoajonline.com/journals/pdf/2052-7896-3-6.pdf

doi: 10.7243/2052-7896-3-6

Continuation of Table 2.

\begin{tabular}{|c|c|c|c|c|c|c|c|c|c|c|}
\hline ID\# & Age & Sex & $\begin{array}{l}\text { Smoking } \\
\text { History }\end{array}$ & $\begin{array}{l}\text { Occupational } \\
\text { History }\end{array}$ & $\begin{array}{l}\text { Asbestos } \\
\text { exposure? }\end{array}$ & $\begin{array}{l}\text { Pleural } \\
\text { plaques }\end{array}$ & $\begin{array}{l}\text { Asbestosis (1982 } \\
\text { CAP-NIOSH) }\end{array}$ & $\begin{array}{l}\text { Ferruginous } \\
\text { bodies OR } \\
\text { Asbestos fibers } \\
\text { (Refer to Table 4) }\end{array}$ & $\begin{array}{l}\text { Pathologic } \\
\text { diagnosis }\end{array}$ & Survival \\
\hline 077 & 72 & M & $\begin{array}{l}30 \text { to } 49- \\
\text { pack years }\end{array}$ & $\begin{array}{l}\text { Service station } \\
\text { attendant; } \\
\text { machinist's mate } \\
\text { in U.S. Navy; } \\
\text { friction and gasket } \\
\text { exposure }\end{array}$ & Yes & $\mathrm{P}$ & $\begin{array}{l}\text { P } \\
\text { Grade } 1\end{array}$ & $\begin{array}{l}\text { Iron stains: } 44 \\
\text { ferruginous } \\
\text { bodies } \\
\text { characteristic of } \\
\text { asbestos bodies in } \\
10.9 \text { square } \mathrm{cm} \text { or } \\
4 \text { asbestos bodies } \\
\text { per square } \mathrm{cm}\end{array}$ & $\begin{array}{l}\text { Adenocarcinoma } \\
\text { of lung, } \\
\text { glandular/tubular } \\
\text { differentiation }\end{array}$ & 20 months \\
\hline $\begin{array}{l}155 / \\
\text { FA10 }\end{array}$ & 62 & M & $\begin{array}{l}10 \text {-pack } \\
\text { years }\end{array}$ & $\begin{array}{l}\text { Electrician } \\
\text { (45 years) }\end{array}$ & Yes & $\mathrm{P}, \mathrm{R}$ & No & $\begin{array}{l}\mathrm{FB} \text { and } \mathrm{AF} \text { above } \\
\text { background }\end{array}$ & $\begin{array}{l}\text { Adenocarcinoma } \\
\text { of lung, } \\
\text { moderately } \\
\text { differentiated; } \\
\text { metastases to } \\
\text { liver, gallbladder, } \\
\text { and thyroid }\end{array}$ & 3 months \\
\hline 056 & 65 & M & $\begin{array}{l}50 \text {-pack } \\
\text { years max }\end{array}$ & Floor coverer & Yes & $\mathrm{P}$ & $\begin{array}{l}\text { P } \\
\text { Grade 2-3 }\end{array}$ & $\begin{array}{l}\text { FB above back- } \\
\text { ground }\end{array}$ & $\begin{array}{l}\text { Adenocarcinoma } \\
\text { of lung, } \\
\text { moderately } \\
\text { to poorly } \\
\text { differentiated }\end{array}$ & 11 months \\
\hline 010 & 74 & M & $\begin{array}{l}\text { Yes - } \\
\text { amount not } \\
\text { specified }\end{array}$ & Unknown & No & No & No & -- & $\begin{array}{l}\text { Adenocarcinoma } \\
\text { of lung, mucin } \\
\text { producing }\end{array}$ & Unknown \\
\hline 030 & 54 & $\mathrm{U}$ & Unknown & Unknown & Unknown & No & No & -- & $\begin{array}{l}\text { Adenocarcinoma } \\
\text { of lung, mucin } \\
\text { producing }\end{array}$ & Unknown \\
\hline 017 & 63 & M & Unknown & Unknown & Unknown & No & No & -- & $\begin{array}{l}\text { Adenocarcinoma } \\
\text { of lung, mucin } \\
\text { producing }\end{array}$ & Unknown \\
\hline 028 & $\mathrm{U}$ & M & Unknown & Unknown & Unknown & No & No & -- & $\begin{array}{l}\text { Adenocarcinoma } \\
\text { of lung, mucin } \\
\text { producing }\end{array}$ & 2 months \\
\hline 012 & 76 & M & Unknown & Unknown & Unknown & No & No & -- & $\begin{array}{l}\text { Adenocarcinoma } \\
\text { of lung, mucin } \\
\text { producing }\end{array}$ & Unknown \\
\hline 007 & 81 & F & $\begin{array}{l}\text { Yes - } \\
\text { amount not } \\
\text { specified }\end{array}$ & Unknown & Unknown & No & No & -- & $\begin{array}{l}\text { Adenocarcinoma } \\
\text { of lung, mucin } \\
\text { producing }\end{array}$ & Unknown \\
\hline 022 & 87 & $\mathrm{~F}$ & Unknown & Unknown & Unknown & No & No & -- & $\begin{array}{l}\text { Adenocarcinoma } \\
\text { of lung, mucin } \\
\text { producing }\end{array}$ & Unknown \\
\hline
\end{tabular}


Hammar et al. Pathology Discovery 2015,

http://www.hoajonline.com/journals/pdf/2052-7896-3-6.pdf

doi: 10.7243/2052-7896-3-6

\begin{tabular}{|c|c|c|c|c|c|c|c|c|c|c|}
\hline ID\# & Age & Sex & $\begin{array}{l}\text { Smoking } \\
\text { History }\end{array}$ & $\begin{array}{l}\text { Occupational } \\
\text { History }\end{array}$ & $\begin{array}{l}\text { Asbestos } \\
\text { exposure? }\end{array}$ & $\begin{array}{l}\text { Pleural } \\
\text { plaques }\end{array}$ & $\begin{array}{l}\text { Asbestosis (1982 } \\
\text { CAP-NIOSH) }\end{array}$ & $\begin{array}{l}\text { Ferruginous } \\
\text { bodies OR } \\
\text { Asbestos fibers } \\
\text { (Refer to Table 4) }\end{array}$ & $\begin{array}{l}\text { Pathologic } \\
\text { diagnosis }\end{array}$ & Survival \\
\hline 029 & 72 & $\mathrm{~F}$ & $\begin{array}{l}\text { Yes - } \\
\text { amount not } \\
\text { specified }\end{array}$ & Clerk & Unknown & No & No & -- & $\begin{array}{l}\text { Adenocarcinoma } \\
\text { of lung, mucin } \\
\text { producing }\end{array}$ & 3 weeks \\
\hline 033 & 69 & M & $\begin{array}{l}70 \text { to } 105- \\
\text { pack years }\end{array}$ & Unknown & Unknown & $\mathrm{P}, \mathrm{R}$ & No & -- & $\begin{array}{l}\text { Adenocarcinoma } \\
\text { of lung, mucin } \\
\text { producing }\end{array}$ & 17 months \\
\hline 032 & 85 & $\mathrm{M}$ & Unknown & Unknown & Unknown & No & No & $\begin{array}{l}\text { Iron stains: } 03 \\
\text { ferruginous } \\
\text { bodies } \\
\text { characteristic of } \\
\text { asbestos bodies }\end{array}$ & $\begin{array}{l}\text { Adenocarcinoma } \\
\text { of lung, mucin } \\
\text { producing }\end{array}$ & Unknown \\
\hline 027 & 83 & M & $\begin{array}{l}40 \text { to } 140- \\
\text { pack years }\end{array}$ & $\begin{array}{l}\text { Rigger, shipfitter } \\
\text { in U.S. Navy }\end{array}$ & Yes & No & No & -- & $\begin{array}{l}\text { Adenocarcinoma } \\
\text { of lung, mucin } \\
\text { producing }\end{array}$ & 11 months \\
\hline 011 & 68 & M & Unknown & Electrician & Yes & No & No & -- & $\begin{array}{l}\text { Adenocarcinoma } \\
\text { of lung, mucin } \\
\text { producing }\end{array}$ & Unknown \\
\hline 031 & 59 & M & Unknown & Unknown & Yes & $\mathrm{P}$ & No & -- & $\begin{array}{l}\text { Adenocarcinoma } \\
\text { of lung, mucin } \\
\text { producing }\end{array}$ & Unknown \\
\hline 009 & 65 & M & $\begin{array}{l}92 \text {-pack } \\
\text { years }\end{array}$ & $\begin{array}{l}\text { Welder, } \\
\text { maintenance man }\end{array}$ & Yes & $\mathrm{P}$ & No & -- & $\begin{array}{l}\text { Adenocarcinoma } \\
\text { of lung, mucin } \\
\text { producing }\end{array}$ & 5 months \\
\hline 014 & 75 & M & $\begin{array}{l}\text { 20-pack } \\
\text { years }\end{array}$ & $\begin{array}{l}\text { Shipfitter, } \\
\text { merchant marine, } \\
\text { plasterer }\end{array}$ & Yes & $\mathrm{P}$ & No & -- & $\begin{array}{l}\text { Adenocarcinoma } \\
\text { of lung, mucin } \\
\text { producing }\end{array}$ & Unknown \\
\hline 023 & 77 & M & $\begin{array}{l}15 \text {-pack } \\
\text { years }\end{array}$ & Refinery worker & Yes & $\mathrm{P}, \mathrm{R}$ & No & -- & $\begin{array}{l}\text { Adenocarcinoma } \\
\text { of lung, mucin } \\
\text { producing }\end{array}$ & Unknown \\
\hline 018 & 73 & M & $\begin{array}{l}20 \text { to } 120- \\
\text { pack years }\end{array}$ & Electrician, welder & Yes & No & $\begin{array}{l}\mathrm{P} \\
\text { Grade } 2\end{array}$ & -- & $\begin{array}{l}\text { Adenocarcinoma } \\
\text { of lung, mucin } \\
\text { producing }\end{array}$ & 2 months \\
\hline 016 & 56 & M & Unknown & $\begin{array}{l}\text { Maintenance } \\
\text { engineer ( } 30 \text { years) }\end{array}$ & Yes & No & $\begin{array}{l}\mathrm{P} \\
\text { Grade } 2\end{array}$ & -- & $\begin{array}{l}\text { Adenocarcinoma } \\
\text { of lung, mucin } \\
\text { producing }\end{array}$ & 20 months \\
\hline 026 & 66 & M & $\begin{array}{l}\text { 20-pack } \\
\text { years }\end{array}$ & $\begin{array}{l}\text { Construction } \\
\text { worker, pipefitter, } \\
\text { hod carrier }\end{array}$ & Yes & No & No & $\begin{array}{l}\text { FB above } \\
\text { background }\end{array}$ & $\begin{array}{l}\text { Adenocarcinoma } \\
\text { of lung, mucin } \\
\text { producing }\end{array}$ & 2 days \\
\hline 041 & 42 & M & $\begin{array}{l}5 \text { to } 10 \text {-pack } \\
\text { years }\end{array}$ & $\begin{array}{l}\text { Pipefitter, HVAC } \\
\text { technician }\end{array}$ & Yes & No & No & $\begin{array}{l}\text { FB above } \\
\text { background }\end{array}$ & $\begin{array}{l}\text { Adenocarcinoma } \\
\text { of lung, mucin } \\
\text { producing }\end{array}$ & 6 months \\
\hline 015 & 71 & M & $\begin{array}{l}60 \text {-pack } \\
\text { years }\end{array}$ & Iron worker & Yes & $\mathrm{P}, \mathrm{R}$ & No & $\begin{array}{l}\text { FB above } \\
\text { background }\end{array}$ & $\begin{array}{l}\text { Adenocarcinoma } \\
\text { of lung, mucin } \\
\text { producing }\end{array}$ & 1 month \\
\hline 034 & 57 & M & Unknown & Unknown & Yes & No & $\begin{array}{l}\mathrm{P} \\
\text { Grade } 1\end{array}$ & $\begin{array}{l}\text { FB above } \\
\text { background }\end{array}$ & $\begin{array}{l}\text { Adenocarcinoma } \\
\text { of lung, mucin } \\
\text { producing }\end{array}$ & Unknown \\
\hline 008 & 55 & M & No & $\begin{array}{l}\text { Lived in close } \\
\text { proximity to } \\
\text { cement plants; } \\
\text { worked for father's } \\
\text { pipeline business; } \\
\text { automotive } \\
\text { maintenance }\end{array}$ & Yes & $\mathrm{P}$ & $\begin{array}{l}\mathrm{P} \\
\text { Grade } 3\end{array}$ & $\begin{array}{l}\text { FB above } \\
\text { background }\end{array}$ & $\begin{array}{l}\text { Adenocarcinoma } \\
\text { of lung, mucin } \\
\text { producing }\end{array}$ & 11 days \\
\hline 013 & 50 & M & $\begin{array}{l}25 \text {-pack } \\
\text { years }\end{array}$ & Boilermaker & Yes & $\mathrm{P}$ & $\begin{array}{l}\mathrm{P} \\
\text { Grade } 2\end{array}$ & $\begin{array}{l}\text { Iron stains: } 46 \\
\text { ferruginous } \\
\text { bodies } \\
\text { characteristic of } \\
\text { asbestos bodies in } \\
\text { lung tissue and } 6 \\
\text { FB in hilar lymph } \\
\text { nodes }\end{array}$ & $\begin{array}{l}\text { Adenocarcinoma } \\
\text { of lung, mucin } \\
\text { producing }\end{array}$ & 3 months \\
\hline
\end{tabular}


Hammar et al. Pathology Discovery 2015,

http://www.hoajonline.com/journals/pdf/2052-7896-3-6.pdf

doi: 10.7243/2052-7896-3-6

Continuation of Table 2.

\begin{tabular}{|c|c|c|c|c|c|c|c|c|c|c|}
\hline ID\# & Age & Sex & $\begin{array}{l}\text { Smoking } \\
\text { History }\end{array}$ & $\begin{array}{l}\text { Occupational } \\
\text { History }\end{array}$ & $\begin{array}{l}\text { Asbestos } \\
\text { exposure? }\end{array}$ & $\begin{array}{l}\text { Pleural } \\
\text { plaques }\end{array}$ & $\begin{array}{l}\text { Asbestosis (1982 } \\
\text { CAP-NIOSH) }\end{array}$ & $\begin{array}{l}\text { Ferruginous } \\
\text { bodies OR } \\
\text { Asbestos fibers } \\
\text { (Refer to Table 4) }\end{array}$ & $\begin{array}{l}\text { Pathologic } \\
\text { diagnosis }\end{array}$ & Survival \\
\hline 035 & 65 & $\mathrm{M}$ & $\begin{array}{l}2 \text { packs } \\
\text { per day; } \\
\text { \# of years } \\
\text { unknown }\end{array}$ & Unknown & Yes & No & No & -- & $\begin{array}{l}\text { Adenocarcinoma } \\
\text { of lung, mucin } \\
\text { producing } \\
\text { with deciduoid } \\
\text { morphology }\end{array}$ & 2 months \\
\hline 020 & 62 & M & 7-pack years & $\begin{array}{l}\text { Plumber, } \\
\text { electrician }\end{array}$ & Yes & $\mathrm{P}, \mathrm{R}$ & No & -- & $\begin{array}{l}\text { Adenocarcinoma } \\
\text { of lung, mucin } \\
\text { producing } \\
\text { with deciduoid } \\
\text { morphology }\end{array}$ & 11 months \\
\hline 036 & 59 & M & $\begin{array}{l}80 \text {-pack } \\
\text { years }\end{array}$ & $\begin{array}{l}\text { Worked at a pipe } \\
\text { company (job title } \\
\text { unknown) }\end{array}$ & Yes & $\mathrm{P}$ & No & $\begin{array}{l}\text { Iron stains: Rare } \\
\text { ferruginous } \\
\text { bodies } \\
\text { characteristic of } \\
\text { asbestos bodies }\end{array}$ & $\begin{array}{l}\text { Adenocarcinoma } \\
\text { of lung, mucin } \\
\text { producing, acinar } \\
\text { type }\end{array}$ & Unknown \\
\hline 037 & 67 & $\mathrm{~F}$ & Unknown & Unknown & Unknown & No & No & -- & $\begin{array}{l}\text { Adenocarcinoma } \\
\text { of lung, mucin } \\
\text { producing, } \\
\text { glandular } \\
\text { differentiation }\end{array}$ & Unknown \\
\hline 024 & 65 & M & $\begin{array}{l}\text { Yes - } 40 \\
\text { years (rate } \\
\text { unknown) }\end{array}$ & $\begin{array}{l}\text { Electrician, } \\
\text { aircraft mechanic }\end{array}$ & Yes & No & No & -- & $\begin{array}{l}\text { Adenocarcinoma } \\
\text { of lung, mucin } \\
\text { producing, } \\
\text { tubular/glandular }\end{array}$ & 22 months \\
\hline 021 & 63 & M & Unknown & Unknown & Unknown & $\mathrm{P}$ & No & -- & $\begin{array}{l}\text { Adenocarcinoma } \\
\text { of lung, mucin } \\
\text { producing, tubu- } \\
\text { lodesmoplastic } \\
\text { type }\end{array}$ & Unknown \\
\hline 075 & 70 & M & $\begin{array}{l}20 \text {-pack } \\
\text { years }\end{array}$ & $\begin{array}{l}\text { Worked with } \\
\text { insulated copper } \\
\text { tubing }\end{array}$ & Yes & No & No & -- & $\begin{array}{l}\text { Adenocarcinoma } \\
\text { of lung, mucin- } \\
\text { producing }\end{array}$ & 1 month \\
\hline 044 & 75 & M & No & $\begin{array}{l}\text { Painter, laborer, } \\
\text { sandblaster }\end{array}$ & Yes & No & $\begin{array}{l}\mathrm{P} \\
\text { Grade } 4\end{array}$ & -- & $\begin{array}{l}\text { Adenocarcinoma } \\
\text { of lung, mucin- } \\
\text { producing }\end{array}$ & 12 months \\
\hline $\begin{array}{l}169 / \\
\text { U04 }\end{array}$ & 63 & $\mathrm{~F}$ & $\begin{array}{l}20 \text {-pack } \\
\text { years }\end{array}$ & $\begin{array}{l}\text { Paraoccupational } \\
\text { and bystander } \\
\text { exposure to } \\
\text { asbestos }\end{array}$ & Yes & No & No & -- & $\begin{array}{l}\text { Adenocarcinoma } \\
\text { of lung, mucin- } \\
\text { producing, } \\
\text { probable } \\
\text { Mullerian origin } \\
\text { based on nuclear } \\
\text { staining for } \\
\text { estrogen receptor } \\
\text { protein }\end{array}$ & 15 months \\
\hline 039 & 73 & M & Unknown & Unknown & Unknown & No & No & -- & $\begin{array}{l}\text { Adenocarcinoma } \\
\text { of lung, not } \\
\text { otherwise } \\
\text { specified }\end{array}$ & Unknown \\
\hline 079 & 75 & $\mathrm{~F}$ & $\begin{array}{l}40+\text { pack } \\
\text { years }\end{array}$ & Unknown & Unknown & No & No & -- & $\begin{array}{l}\text { Adenocarcinoma } \\
\text { of lung, not } \\
\text { otherwise } \\
\text { specified }\end{array}$ & Unknown \\
\hline 085 & 75 & $\mathrm{~F}$ & $\begin{array}{l}\text { Yes - } \\
\text { amount not } \\
\text { specified }\end{array}$ & Unknown & Unknown & No & No & -- & $\begin{array}{l}\text { Adenocarcinoma } \\
\text { of lung, not } \\
\text { otherwise } \\
\text { specified }\end{array}$ & Unknown \\
\hline $\begin{array}{l}\text { 161/ } \\
\text { FA16 }\end{array}$ & $\mathrm{U}$ & M & Unknown & Unknown & Unknown & No & No & $\begin{array}{l}\text { AF above } \\
\text { background }\end{array}$ & $\begin{array}{l}\text { Adenocarcinoma } \\
\text { of lung, not } \\
\text { otherwise } \\
\text { specified }\end{array}$ & Unknown \\
\hline
\end{tabular}


Hammar et al. Pathology Discovery 2015,

\section{Continuation of Table 2.}

\begin{tabular}{|c|c|c|c|c|c|c|c|c|c|c|}
\hline ID\# & Age & Sex & $\begin{array}{l}\text { Smoking } \\
\text { History }\end{array}$ & $\begin{array}{l}\text { Occupational } \\
\text { History }\end{array}$ & $\begin{array}{l}\text { Asbestos } \\
\text { exposure? }\end{array}$ & $\begin{array}{l}\text { Pleural } \\
\text { plaques }\end{array}$ & $\begin{array}{l}\text { Asbestosis (1982 } \\
\text { CAP-NIOSH) }\end{array}$ & $\begin{array}{l}\text { Ferruginous } \\
\text { bodies OR } \\
\text { Asbestos fibers } \\
\text { (Refer to Table 4) }\end{array}$ & $\begin{array}{l}\text { Pathologic } \\
\text { diagnosis }\end{array}$ & Survival \\
\hline 088 & 58 & $\mathrm{M}$ & $\begin{array}{l}\text { Yes - } \\
\text { amount not } \\
\text { specified }\end{array}$ & Unknown & Unknown & No & No & $\begin{array}{l}\text { FB above } \\
\text { background; } 2 \mathrm{AB} \\
\text { in iron stained } \\
\text { sections }\end{array}$ & $\begin{array}{l}\text { Adenocarcinoma } \\
\text { of lung, not } \\
\text { otherwise } \\
\text { specified }\end{array}$ & Unknown \\
\hline $\begin{array}{l}164 / \\
\text { FA19 }\end{array}$ & 64 & M & $\begin{array}{l}1 \text { pack } \\
\text { per day; } \\
\text { \# of years } \\
\text { unknown }\end{array}$ & Unknown & Unknown & No & No & $\begin{array}{l}\text { FB below } \\
\text { background; AF } \\
\text { above background }\end{array}$ & $\begin{array}{l}\text { Adenocarcinoma } \\
\text { of lung, not } \\
\text { otherwise } \\
\text { specified }\end{array}$ & Unknown \\
\hline 047 & 68 & M & Unknown & Carpenter, laborer & Yes & No & No & -- & $\begin{array}{l}\text { Adenocarcinoma } \\
\text { of lung, not } \\
\text { otherwise } \\
\text { specified }\end{array}$ & 3 days \\
\hline 074 & 82 & M & Unknown & Unknown & Yes & No & No & -- & $\begin{array}{l}\text { Adenocarcinoma } \\
\text { of lung, not } \\
\text { otherwise } \\
\text { specified }\end{array}$ & Unknown \\
\hline 052 & 70 & M & $\begin{array}{l}140 \text { to } 160- \\
\text { pack years }\end{array}$ & $\begin{array}{l}\text { Pipefitter, } \\
\text { steamfitter, } \\
\text { plumber, lagger }\end{array}$ & Yes & No & No & -- & $\begin{array}{l}\text { Adenocarcinoma } \\
\text { of lung, not } \\
\text { otherwise } \\
\text { specified }\end{array}$ & 3 months \\
\hline 045 & 67 & M & $\begin{array}{l}100 \text {-pack } \\
\text { years }\end{array}$ & $\begin{array}{l}\text { Engineer and } \\
\text { sailor on barges }\end{array}$ & Yes & No & No & -- & $\begin{array}{l}\text { Adenocarcinoma } \\
\text { of lung, not } \\
\text { otherwise } \\
\text { specified }\end{array}$ & 5 months \\
\hline 055 & 54 & M & $\begin{array}{l}\text { 36-pack } \\
\text { years }\end{array}$ & $\begin{array}{l}\text { Rigger, bricklayer's } \\
\text { helper, } \\
\text { boilermaker }\end{array}$ & Yes & No & No & -- & $\begin{array}{l}\text { Adenocarcinoma } \\
\text { of lung, not } \\
\text { otherwise } \\
\text { specified }\end{array}$ & Unknown \\
\hline 059 & 51 & M & $\begin{array}{l}20 \text {-pack } \\
\text { years }\end{array}$ & Electrician & Yes & No & No & -- & $\begin{array}{l}\text { Adenocarcinoma } \\
\text { of lung, not } \\
\text { otherwise } \\
\text { specified }\end{array}$ & 2 months \\
\hline 054 & 64 & M & $\begin{array}{l}1 / 2 \text { to } 2 \\
\text { packs per } \\
\text { day until } \\
1970\end{array}$ & Welder, pipefitter & Yes & No & No & -- & $\begin{array}{l}\text { Adenocarcinoma } \\
\text { of lung, not } \\
\text { otherwise } \\
\text { specified }\end{array}$ & 3 months \\
\hline 072 & 78 & M & 5-pack years & Longshoreman & Yes & No & No & -- & $\begin{array}{l}\text { Adenocarcinoma } \\
\text { of lung, not } \\
\text { otherwise } \\
\text { specified }\end{array}$ & $<1$ year \\
\hline 046 & 68 & M & $\begin{array}{l}\text { 12-pack } \\
\text { years }\end{array}$ & $\begin{array}{l}\text { Sheet metal } \\
\text { worker in U.S. } \\
\text { Navy }\end{array}$ & Yes & No & No & -- & $\begin{array}{l}\text { Adenocarcinoma } \\
\text { of lung, not } \\
\text { otherwise } \\
\text { specified }\end{array}$ & 3 months \\
\hline 062 & 68 & M & $\begin{array}{l}48 \text { to } 96- \\
\text { pack years }\end{array}$ & $\begin{array}{l}\text { Automotive } \\
\text { mechanic, } \\
\text { carpenter }\end{array}$ & Yes & $\mathrm{P}$ & No & -- & $\begin{array}{l}\text { Adenocarcinoma } \\
\text { of lung, not } \\
\text { otherwise } \\
\text { specified }\end{array}$ & Unknown \\
\hline 053 & 68 & M & $\begin{array}{l}25 \text {-pack } \\
\text { years }\end{array}$ & $\begin{array}{l}\text { Electrical } \\
\text { company em- } \\
\text { ployee (job title } \\
\text { not specified) }\end{array}$ & Yes & $\mathrm{P}$ & No & -- & $\begin{array}{l}\text { Adenocarcinoma } \\
\text { of lung, not } \\
\text { otherwise } \\
\text { specified }\end{array}$ & Unknown \\
\hline 078 & 79 & M & $\begin{array}{l}30 \text { to } 60- \\
\text { pack years }\end{array}$ & Plumber & Yes & $\mathrm{P}$ & No & -- & $\begin{array}{l}\text { Adenocarcinoma } \\
\text { of lung, not } \\
\text { otherwise } \\
\text { specified }\end{array}$ & 2 months \\
\hline 058 & 64 & M & $\begin{array}{l}\text { 21-pack } \\
\text { years }\end{array}$ & Plumber & Yes & $\mathrm{P}, \mathrm{R}$ & No & -- & $\begin{array}{l}\text { Adenocarcinoma } \\
\text { of lung, not } \\
\text { otherwise } \\
\text { specified }\end{array}$ & Unknown \\
\hline
\end{tabular}


Hammar et al. Pathology Discovery 2015,

http://www.hoajonline.com/journals/pdf/2052-7896-3-6.pdf

doi: 10.7243/2052-7896-3-6

Continuation of Table 2.

\begin{tabular}{|c|c|c|c|c|c|c|c|c|c|c|}
\hline ID\# & Age & Sex & $\begin{array}{l}\text { Smoking } \\
\text { History }\end{array}$ & $\begin{array}{l}\text { Occupational } \\
\text { History }\end{array}$ & $\begin{array}{l}\text { Asbestos } \\
\text { exposure? }\end{array}$ & $\begin{array}{l}\text { Pleural } \\
\text { plaques }\end{array}$ & $\begin{array}{l}\text { Asbestosis (1982 } \\
\text { CAP-NIOSH) }\end{array}$ & $\begin{array}{l}\text { Ferruginous } \\
\text { bodies OR } \\
\text { Asbestos fibers } \\
\text { (Refer to Table 4) }\end{array}$ & $\begin{array}{l}\text { Pathologic } \\
\text { diagnosis }\end{array}$ & Survival \\
\hline 057 & 71 & $\mathrm{M}$ & $\begin{array}{l}30 \text {-pack } \\
\text { years }\end{array}$ & Welder, pipefitter & Yes & $\mathrm{R}$ & No & -- & $\begin{array}{l}\text { Adenocarcinoma } \\
\text { of lung, not } \\
\text { otherwise } \\
\text { specified }\end{array}$ & 24 months \\
\hline 071 & 65 & M & $\begin{array}{l}\text { 30-pack } \\
\text { years }\end{array}$ & $\begin{array}{l}\text { Sheet metal } \\
\text { worker }\end{array}$ & Yes & $\mathrm{R}$ & No & -- & $\begin{array}{l}\text { Adenocarcinoma } \\
\text { of lung, not } \\
\text { otherwise } \\
\text { specified }\end{array}$ & 2 months \\
\hline 086 & 68 & M & $\begin{array}{l}52 \text { to } 66- \\
\text { pack years }\end{array}$ & Boiler tender & Yes & $\mathrm{R}$ & No & -- & $\begin{array}{l}\text { Adenocarcinoma } \\
\text { of lung, not } \\
\text { otherwise } \\
\text { specified }\end{array}$ & 9 months \\
\hline 070 & 65 & $\mathrm{M}$ & Unknown & U.S. Navy & Yes & $\mathrm{R}$ & No & -- & $\begin{array}{l}\text { Adenocarcinoma } \\
\text { of lung, not } \\
\text { otherwise } \\
\text { specified }\end{array}$ & Unknown \\
\hline 060 & 70 & M & $\begin{array}{l}45 \text { to } 72- \\
\text { pack years }\end{array}$ & $\begin{array}{l}\text { Bricklayer, laborer, } \\
\text { crane operator, } \\
\text { machinist, } \\
\text { rotoblast operator }\end{array}$ & Yes & $\mathrm{R}$ & No & -- & $\begin{array}{l}\text { Adenocarcinoma } \\
\text { of lung, not } \\
\text { otherwise } \\
\text { specified }\end{array}$ & 22 months \\
\hline 064 & 83 & $\mathrm{M}$ & $\begin{array}{l}50 \text {-pack } \\
\text { years }\end{array}$ & Unknown & Yes & $\mathrm{R}$ & No & -- & $\begin{array}{l}\text { Adenocarcinoma } \\
\text { of lung, not } \\
\text { otherwise } \\
\text { specified }\end{array}$ & Unknown \\
\hline 049 & 59 & $\mathrm{M}$ & $\begin{array}{l}29 \text { to } 80- \\
\text { pack years }\end{array}$ & $\begin{array}{l}\text { Pipefitter, } \\
\text { steamfitter }\end{array}$ & Yes & No & $\begin{array}{l}\mathrm{P} \\
\text { Grade } 3\end{array}$ & -- & $\begin{array}{l}\text { Adenocarcinoma } \\
\text { of lung, not } \\
\text { otherwise } \\
\text { specified }\end{array}$ & 4 days \\
\hline 084 & 64 & $\mathrm{M}$ & $\begin{array}{l}\text { Yes - } \\
\text { amount not } \\
\text { specified }\end{array}$ & Pipefitter & Yes & $\mathrm{P}$ & $\begin{array}{l}\mathrm{P} \\
\text { Grade 1-2 }\end{array}$ & -- & $\begin{array}{l}\text { Adenocarcinoma } \\
\text { of lung, not } \\
\text { otherwise } \\
\text { specified }\end{array}$ & 2 months \\
\hline 042 & 61 & $\mathrm{M}$ & $\begin{array}{l}\text { 82-pack } \\
\text { years }\end{array}$ & $\begin{array}{l}\text { Plasterer, } \\
\text { carpenter }\end{array}$ & Yes & $\mathrm{P}, \mathrm{R}$ & $\begin{array}{l}\mathrm{P} \\
\text { Grade 1-2 }\end{array}$ & -- & $\begin{array}{l}\text { Adenocarcinoma } \\
\text { of lung, not } \\
\text { otherwise } \\
\text { specified }\end{array}$ & 11 months \\
\hline 061 & 65 & $\mathrm{M}$ & Unknown & $\begin{array}{l}\text { Laborer, heavy } \\
\text { equipment } \\
\text { operator at an } \\
\text { aluminum plant }\end{array}$ & Yes & $\mathrm{R}$ & $\begin{array}{l}\text { P } \\
\text { Grade } 2\end{array}$ & -- & $\begin{array}{l}\text { Adenocarcinoma } \\
\text { of lung, not } \\
\text { otherwise } \\
\text { specified }\end{array}$ & 2 months \\
\hline 073 & 71 & M & $\begin{array}{l}27 \text {-pack } \\
\text { years }\end{array}$ & Longshoreman & Yes & $\mathrm{P}$ & $\mathrm{R}$ & -- & $\begin{array}{l}\text { Adenocarcinoma } \\
\text { of lung, not } \\
\text { otherwise } \\
\text { specified }\end{array}$ & 8 months \\
\hline 066 & 77 & $\mathrm{M}$ & No & Plasterer & Yes & No & No & $\begin{array}{l}\text { FB above } \\
\text { background }\end{array}$ & $\begin{array}{l}\text { Adenocarcinoma } \\
\text { of lung, not } \\
\text { otherwise } \\
\text { specified }\end{array}$ & 6 months \\
\hline 050 & 58 & M & $\begin{array}{l}40 \text {-pack } \\
\text { years }\end{array}$ & $\begin{array}{l}\text { Sheet metal } \\
\text { worker }\end{array}$ & Yes & No & No & $\begin{array}{l}\text { FB above } \\
\text { background }\end{array}$ & $\begin{array}{l}\text { Adenocarcinoma } \\
\text { of lung, not } \\
\text { otherwise } \\
\text { specified }\end{array}$ & 15 months \\
\hline 067 & 80 & $\mathrm{M}$ & Unknown & Asbestos worker & Yes & $\mathrm{P}$ & No & $\begin{array}{l}\text { FB above } \\
\text { background }\end{array}$ & $\begin{array}{l}\text { Adenocarcinoma } \\
\text { of lung, not } \\
\text { otherwise } \\
\text { specified }\end{array}$ & Unknown \\
\hline 081 & 65 & $\mathrm{M}$ & $\begin{array}{l}\text { Yes - } \\
\text { amount not } \\
\text { specified }\end{array}$ & $\begin{array}{l}\text { Asbestos brake } \\
\text { plant worker }\end{array}$ & Yes & $\mathrm{P}$ & No & $\begin{array}{l}\text { FB above } \\
\text { background }\end{array}$ & $\begin{array}{l}\text { Adenocarcinoma } \\
\text { of lung, not } \\
\text { otherwise } \\
\text { specified }\end{array}$ & Unknown \\
\hline
\end{tabular}


Hammar et al. Pathology Discovery 2015,

Continuation of Table 2.

\begin{tabular}{|c|c|c|c|c|c|c|c|c|c|c|}
\hline ID\# & Age & Sex & $\begin{array}{l}\text { Smoking } \\
\text { History }\end{array}$ & $\begin{array}{l}\text { Occupational } \\
\text { History }\end{array}$ & $\begin{array}{l}\text { Asbestos } \\
\text { exposure? }\end{array}$ & $\begin{array}{l}\text { Pleural } \\
\text { plaques }\end{array}$ & $\begin{array}{l}\text { Asbestosis (1982 } \\
\text { CAP-NIOSH) }\end{array}$ & $\begin{array}{l}\text { Ferruginous } \\
\text { bodies OR } \\
\text { Asbestos fibers } \\
\text { (Refer to Table 4) }\end{array}$ & $\begin{array}{l}\text { Pathologic } \\
\text { diagnosis }\end{array}$ & Survival \\
\hline 063 & 76 & $\mathrm{M}$ & 2-pack years & $\begin{array}{l}\text { Pipefitter in U.S. } \\
\text { Army }\end{array}$ & Yes & $\mathrm{P}, \mathrm{R}$ & $\begin{array}{l}\mathrm{P} \\
\text { Grade 2-3 }\end{array}$ & $\begin{array}{l}\text { FB above } \\
\text { background }\end{array}$ & $\begin{array}{l}\text { Adenocarcinoma } \\
\text { of lung, not } \\
\text { otherwise } \\
\text { specified }\end{array}$ & Unknown \\
\hline $\begin{array}{l}152 / \\
\text { FA07 }\end{array}$ & 69 & M & $\begin{array}{l}55 \text { to } 100- \\
\text { pack years }\end{array}$ & $\begin{array}{l}\text { Steamfitter and } \\
\text { plumber ( } 25 \text { years })\end{array}$ & Yes & $\mathrm{P}$ & $\begin{array}{l}\mathrm{P} \\
\text { Grade 3-4 }\end{array}$ & $\begin{array}{l}\text { FB and AF above } \\
\text { background }\end{array}$ & $\begin{array}{l}\text { Adenocarcinoma } \\
\text { of lung, not } \\
\text { otherwise } \\
\text { specified }\end{array}$ & 20 months \\
\hline $\begin{array}{l}149 / \\
\text { FA04 }\end{array}$ & 75 & M & $\begin{array}{l}100 \text {-pack } \\
\text { years }\end{array}$ & $\begin{array}{l}\text { Shipyard } \\
\text { electrician }(35 \\
\text { years) }\end{array}$ & Yes & $\mathrm{P}$ & $\begin{array}{l}\mathrm{P} \\
\text { Grade 3-4 }\end{array}$ & $\begin{array}{l}\text { FB and AF above } \\
\text { background }\end{array}$ & $\begin{array}{l}\text { Adenocarcinoma } \\
\text { of lung, not } \\
\text { otherwise } \\
\text { specified }\end{array}$ & 7 months \\
\hline 065 & 75 & M & No & $\begin{array}{l}\text { Laborer, mechanic, } \\
\text { heavy equipment } \\
\text { operator, lathe } \\
\text { operator }\end{array}$ & Yes & $\mathrm{P}$ & No & $\begin{array}{l}\text { Iron stains: } 01 \\
\text { ferruginous body } \\
\text { characteristic of } \\
\text { an asbestos body }\end{array}$ & $\begin{array}{l}\text { Adenocarcinoma } \\
\text { of lung, not } \\
\text { otherwise } \\
\text { specified }\end{array}$ & Unknown \\
\hline 083 & 52 & M & No & Carpenter & Yes & No & No & $\begin{array}{l}\text { Iron stains: } 02 \\
\text { ferruginous } \\
\text { bodies } \\
\text { characteristic of } \\
\text { asbestos bodies }\end{array}$ & $\begin{array}{l}\text { Adenocarcinoma } \\
\text { of lung, not } \\
\text { otherwise } \\
\text { specified }\end{array}$ & 5 months \\
\hline 087 & 84 & $\mathrm{M}$ & $\begin{array}{l}35 \text {-pack } \\
\text { years }\end{array}$ & $\begin{array}{l}\text { U.S. Navy Seaman } \\
\text { 1st Class and } \\
\text { Gunner's Mate; } \\
\text { Marine electrician } \\
\text { and mechanic in } \\
\text { shipyards; drywall } \\
\text { work }\end{array}$ & Yes & $\mathrm{P}, \mathrm{R}$ & $\begin{array}{l}\mathrm{P} \\
\text { Grade 2-3 }\end{array}$ & $\begin{array}{l}\text { Iron stains: } 03 \\
\text { ferruginous } \\
\text { bodies } \\
\text { characteristic of } \\
\text { asbestos bodies }\end{array}$ & $\begin{array}{l}\text { Adenocarcinoma } \\
\text { of lung, not } \\
\text { otherwise } \\
\text { specified }\end{array}$ & 6 months \\
\hline 069 & 71 & M & 7-pack years & $\begin{array}{l}\text { Boiler tender/ } \\
\text { fireman in US } \\
\text { Navy }\end{array}$ & Yes & $\mathrm{P}, \mathrm{R}$ & $\begin{array}{l}\mathrm{P} \\
\text { Grade } 4\end{array}$ & $\begin{array}{l}\text { Iron stains: } 06 \\
\text { ferruginous } \\
\text { bodies } \\
\text { characteristic of } \\
\text { asbestos bodies }\end{array}$ & $\begin{array}{l}\text { Adenocarcinoma } \\
\text { of lung, not } \\
\text { otherwise } \\
\text { specified }\end{array}$ & 1 month \\
\hline 043 & 71 & M & Minimal & $\begin{array}{l}\text { Machinist Mate, } \\
\text { pipefitter, brake } \\
\text { work, drywall } \\
\text { work }\end{array}$ & Yes & $\mathrm{P}, \mathrm{R}$ & $\begin{array}{l}\mathrm{P} \\
\text { Grade } 2\end{array}$ & $\begin{array}{l}\text { Iron stains: } 12 \\
\text { ferruginous } \\
\text { bodies } \\
\text { characteristic of } \\
\text { asbestos bodies }\end{array}$ & $\begin{array}{l}\text { Adenocarcinoma } \\
\text { of lung, not } \\
\text { otherwise } \\
\text { specified }\end{array}$ & 7 months \\
\hline $\begin{array}{l}163 / \\
\text { FA18 }\end{array}$ & 62 & M & Unknown & Unknown & Unknown & No & No & $\begin{array}{l}\text { FB below } \\
\text { background; AF } \\
\text { above background }\end{array}$ & $\begin{array}{l}\text { Adenocarcinoma } \\
\text { of lung, not } \\
\text { otherwise } \\
\text { specified; } \\
\text { metastases to } \\
\text { liver and kidney }\end{array}$ & 6 months \\
\hline $\begin{array}{l}157 / \\
\text { FA12 }\end{array}$ & 64 & M & Unknown & $\begin{array}{l}\text { Shipyard insulator } \\
\text { \& shipwright ( } 5 \\
\text { years); lineman }\end{array}$ & Yes & $\mathrm{P}$ & $\begin{array}{l}\mathrm{P} \\
\text { Grade 2-3 }\end{array}$ & $\begin{array}{l}\mathrm{FB} \text { and } \mathrm{AF} \text { above } \\
\text { background }\end{array}$ & $\begin{array}{l}\text { Adenocarcinoma } \\
\text { of lung, not } \\
\text { otherwise } \\
\text { specified; } \\
\text { metastases to } \\
\text { mesentery, } \\
\text { omentum, and } \\
\text { other peritoneal } \\
\text { surfaces }\end{array}$ & 8 months \\
\hline $\begin{array}{l}154 / \\
\text { FA09 }\end{array}$ & 71 & M & $\begin{array}{l}\text { 39-pack } \\
\text { years }\end{array}$ & $\begin{array}{l}\text { Wiper \& oiler ( } 3 \\
\text { years); insulator } \\
\text { \& pipefitter ( } 35 \\
\text { years) }\end{array}$ & Yes & $\mathrm{P}$ & $\begin{array}{l}\mathrm{P} \\
\text { Grade } 1\end{array}$ & $\begin{array}{l}\text { FB and AF above } \\
\text { background }\end{array}$ & $\begin{array}{l}\text { Adenocarcinoma } \\
\text { of lung, papillary } \\
\text { (type II pneu- } \\
\text { mocyte origin by } \\
\text { EM); metastases } \\
\text { to left lung, } \\
\text { omentum, and } \\
\text { lymph nodes }\end{array}$ & 14 months \\
\hline
\end{tabular}


Hammar et al. Pathology Discovery 2015,

http://www.hoajonline.com/journals/pdf/2052-7896-3-6.pdf

doi: 10.7243/2052-7896-3-6

\begin{tabular}{|c|c|c|c|c|c|c|c|c|c|c|}
\hline ID\# & Age & Sex & $\begin{array}{l}\text { Smoking } \\
\text { History }\end{array}$ & $\begin{array}{l}\text { Occupational } \\
\text { History }\end{array}$ & $\begin{array}{l}\text { Asbestos } \\
\text { exposure? }\end{array}$ & $\begin{array}{l}\text { Pleural } \\
\text { plaques }\end{array}$ & $\begin{array}{l}\text { Asbestosis (1982 } \\
\text { CAP-NIOSH) }\end{array}$ & $\begin{array}{l}\text { Ferruginous } \\
\text { bodies OR } \\
\text { Asbestos fibers } \\
\text { (Refer to Table } 4)\end{array}$ & $\begin{array}{l}\text { Pathologic } \\
\text { diagnosis }\end{array}$ & Survival \\
\hline 090 & 57 & $\mathrm{~F}$ & $\begin{array}{l}42 \text { to } 50- \\
\text { pack years }\end{array}$ & $\begin{array}{l}\text { Domestic } \\
\text { exposure from } \\
\text { father (shipyard } \\
\text { mechanic), } \\
\text { husband } \\
\text { (assembler } \\
\text { at aircraft } \\
\text { manufacturing } \\
\text { plant), and } \\
\text { ex-husband } \\
\text { (contractor) }\end{array}$ & $\begin{array}{l}\text { Para-occupa- } \\
\text { tional }\end{array}$ & $\mathrm{R}$ & No & -- & $\begin{array}{l}\text { Adenocarcinoma } \\
\text { of lung, papillary } \\
\text { type }\end{array}$ & Unknown \\
\hline 005 & 64 & $\mathrm{~F}$ & Unknown & Unknown & Unknown & No & No & -- & $\begin{array}{l}\text { Adenocarcinoma } \\
\text { of lung, papillary } \\
\text { type }\end{array}$ & Unknown \\
\hline 089 & 52 & $\mathrm{M}$ & No & $\begin{array}{l}\text { Smelter and } \\
\text { refinery worker }\end{array}$ & Yes & No & No & $\begin{array}{l}\text { FB above } \\
\text { background }\end{array}$ & $\begin{array}{l}\text { Adenocarcinoma } \\
\text { of lung, papillary } \\
\text { type }\end{array}$ & 10 months \\
\hline $\begin{array}{l}165 / \\
\text { FA20 }\end{array}$ & 53 & $\mathrm{M}$ & $\begin{array}{l}20 \text { to } 21- \\
\text { pack years }\end{array}$ & $\begin{array}{l}\text { Laborer, carpenter, } \\
\text { service station } \\
\text { manager }\end{array}$ & Yes & No & No & $\begin{array}{l}\text { FB below } \\
\text { background; AF } \\
\text { above background }\end{array}$ & $\begin{array}{l}\text { Adenocarcinoma } \\
\text { of lung, } \\
\text { pleomorphic } \\
\text { type, poorly } \\
\text { differentiated }\end{array}$ & Unknown \\
\hline 103 & 66 & $\mathrm{~F}$ & $\begin{array}{l}\text { Yes - } \\
\text { amount not } \\
\text { specified }\end{array}$ & $\begin{array}{l}\text { Analyst } \\
\text { (management) in } \\
\text { shipyard }\end{array}$ & Bystander & No & No & -- & $\begin{array}{l}\text { Adenocarcinoma } \\
\text { of lung, poorly } \\
\text { differentiated }\end{array}$ & 29 months \\
\hline 104 & 77 & $\mathrm{M}$ & Unknown & Unknown & Unknown & No & No & -- & $\begin{array}{l}\text { Adenocarcinoma } \\
\text { of lung, poorly } \\
\text { differentiated }\end{array}$ & Unknown \\
\hline 099 & 85 & $\mathrm{M}$ & $\begin{array}{l}\text { Yes - } \\
\text { amount not } \\
\text { specified }\end{array}$ & $\begin{array}{l}\text { Engineer for } \\
\text { government }\end{array}$ & Unknown & No & No & $\begin{array}{l}\text { FB above } \\
\text { background }\end{array}$ & $\begin{array}{l}\text { Adenocarcinoma } \\
\text { of lung, poorly } \\
\text { differentiated }\end{array}$ & 15 months \\
\hline 096 & 63 & M & Unknown & Unknown & Unknown & $\mathrm{P}$ & $\begin{array}{l}\text { P } \\
\text { Grade } 3\end{array}$ & $\begin{array}{l}\text { FB above } \\
\text { background }\end{array}$ & $\begin{array}{l}\text { Adenocarcinoma } \\
\text { of lung, poorly } \\
\text { differentiated }\end{array}$ & Unknown \\
\hline 097 & 64 & $\mathrm{M}$ & $\begin{array}{l}1 \text { pack } \\
\text { per day; } \\
\text { \# of years } \\
\text { unknown }\end{array}$ & Unknown & Unknown & No & No & $\begin{array}{l}\text { FB below } \\
\text { background }\end{array}$ & $\begin{array}{l}\text { Adenocarcinoma } \\
\text { of lung, poorly } \\
\text { differentiated }\end{array}$ & Unknown \\
\hline 106 & 66 & M & $\begin{array}{l}20 \text {-pack } \\
\text { years }\end{array}$ & $\begin{array}{l}\text { Coal miner/ } \\
\text { dragline operator } \\
\text { stripping coal }\end{array}$ & Yes & No & No & -- & $\begin{array}{l}\text { Adenocarcinoma } \\
\text { of lung, poorly } \\
\text { differentiated }\end{array}$ & 14 months \\
\hline 135 & 63 & $\mathrm{M}$ & $\begin{array}{l}41 \text {-pack } \\
\text { years }\end{array}$ & Engineer & Yes & No & No & -- & $\begin{array}{l}\text { Adenocarcinoma } \\
\text { of lung, poorly } \\
\text { differentiated }\end{array}$ & Unknown \\
\hline 101 & 70 & M & No & $\begin{array}{l}\text { Tank mechanic } \\
\text { in U.S. Army } \\
\text { (exposed to } \\
\text { friction products); } \\
\text { Ranch operator } \\
\text { - performed } \\
\text { repairs on farm } \\
\text { equipment- } \\
\text { friction }\end{array}$ & Yes & No & No & -- & $\begin{array}{l}\text { Adenocarcinoma } \\
\text { of lung, poorly } \\
\text { differentiated }\end{array}$ & 6 weeks \\
\hline 094 & 77 & M & $\begin{array}{l}\text { Yes - } \\
\text { amount not } \\
\text { specified }\end{array}$ & Longshoreman & Yes & No & No & -- & $\begin{array}{l}\text { Adenocarcinoma } \\
\text { of lung, poorly } \\
\text { differentiated }\end{array}$ & Unknown \\
\hline 102 & 49 & M & $\begin{array}{l}28 \text { years } \\
\text { (rate un- } \\
\text { known) }\end{array}$ & Insulator & Yes & No & No & -- & $\begin{array}{l}\text { Adenocarcinoma } \\
\text { of lung, poorly } \\
\text { differentiated }\end{array}$ & Unknown \\
\hline
\end{tabular}


Hammar et al. Pathology Discovery 2015,

http://www.hoajonline.com/journals/pdf/2052-7896-3-6.pdf

doi: 10.7243/2052-7896-3-6

Continuation of Table 2.

\begin{tabular}{|c|c|c|c|c|c|c|c|c|c|c|}
\hline ID\# & Age & Sex & $\begin{array}{l}\text { Smoking } \\
\text { History }\end{array}$ & $\begin{array}{l}\text { Occupational } \\
\text { History }\end{array}$ & $\begin{array}{l}\text { Asbestos } \\
\text { exposure? }\end{array}$ & $\begin{array}{l}\text { Pleural } \\
\text { plaques }\end{array}$ & $\begin{array}{l}\text { Asbestosis (1982 } \\
\text { CAP-NIOSH) }\end{array}$ & $\begin{array}{l}\text { Ferruginous } \\
\text { bodies OR } \\
\text { Asbestos fibers } \\
\text { (Refer to Table 4) }\end{array}$ & $\begin{array}{l}\text { Pathologic } \\
\text { diagnosis }\end{array}$ & Survival \\
\hline 095 & 69 & $\mathrm{M}$ & Unknown & Shipyard worker & Yes & No & No & $\begin{array}{l}\text { FB above } \\
\text { background }\end{array}$ & $\begin{array}{l}\text { Adenocarcinoma } \\
\text { of lung, poorly } \\
\text { differentiated }\end{array}$ & Unknown \\
\hline 093 & 40 & M & No & $\begin{array}{l}\text { Mechanic, } \\
\text { machinist }\end{array}$ & Yes & No & No & $\begin{array}{l}\text { FB above } \\
\text { background }\end{array}$ & $\begin{array}{l}\text { Adenocarcinoma } \\
\text { of lung, poorly } \\
\text { differentiated }\end{array}$ & Unknown \\
\hline 092 & 48 & M & $\begin{array}{l}52 \text {-pack } \\
\text { years }\end{array}$ & $\begin{array}{l}\text { U.S. Army; } \\
\text { bystander during } \\
\text { remodeling/ } \\
\text { construction of } \\
\text { drug store }\end{array}$ & Yes & No & No & $\begin{array}{l}\text { FB above } \\
\text { background }\end{array}$ & $\begin{array}{l}\text { Adenocarcinoma } \\
\text { of lung, poorly } \\
\text { differentiated }\end{array}$ & 11 months \\
\hline 091 & 55 & M & $\begin{array}{l}\text { 76-pack } \\
\text { years }\end{array}$ & $\begin{array}{l}\text { Heavy truck } \\
\text { and equipment } \\
\text { mechanic }\end{array}$ & Yes & No & $\begin{array}{l}\mathrm{P} \\
\text { Grade } 2\end{array}$ & $\begin{array}{l}\text { FB above } \\
\text { background }\end{array}$ & $\begin{array}{l}\text { Adenocarcinoma } \\
\text { of lung, poorly } \\
\text { differentiated }\end{array}$ & 5 months \\
\hline 098 & 60 & M & $\begin{array}{l}22 \text { to } 33- \\
\text { pack years }\end{array}$ & $\begin{array}{l}\text { Electrician, brick- } \\
\text { layer }\end{array}$ & Yes & $\mathrm{P}, \mathrm{R}$ & $\begin{array}{l}\mathrm{P} \\
\text { Grade } 2\end{array}$ & $\begin{array}{l}\text { FB above } \\
\text { background }\end{array}$ & $\begin{array}{l}\text { Adenocarcinoma } \\
\text { of lung, poorly } \\
\text { differentiated }\end{array}$ & Unknown \\
\hline 100 & 68 & M & No & $\begin{array}{l}\text { Machinist, } \\
\text { boatswains mate, } \\
\text { marine mechanic; } \\
\text { home remodeling; } \\
\text { automotive repair }\end{array}$ & Yes & $\mathrm{P}$ & No & $\begin{array}{l}\text { Iron stains: } 01 \\
\text { ferruginous body } \\
\text { characteristic of } \\
\text { an asbestos body }\end{array}$ & $\begin{array}{l}\text { Adenocarcinoma } \\
\text { of lung, poorly } \\
\text { differentiated }\end{array}$ & 6 months \\
\hline 105 & 67 & $\mathrm{~F}$ & $\begin{array}{l}\text { 23-pack } \\
\text { years }\end{array}$ & $\begin{array}{l}\text { Laborer at a brake } \\
\text { factory assembling } \\
\text { brake pads }\end{array}$ & Yes & $\mathrm{P}$ & $\begin{array}{l}\mathrm{P} \\
\text { Grade } 3\end{array}$ & $\begin{array}{l}\text { Iron stains: } 05 \\
\text { ferruginous } \\
\text { bodies } \\
\text { characteristic of } \\
\text { asbestos bodies }\end{array}$ & $\begin{array}{l}\text { Adenocarcinoma } \\
\text { of lung, poorly } \\
\text { differentiated }\end{array}$ & 3 months \\
\hline $\begin{array}{l}\text { 158/ } \\
\text { FA13 }\end{array}$ & $\mathrm{U}$ & M & Unknown & Unknown & Unknown & $\mathrm{P}$ & $\begin{array}{l}\mathrm{P} \\
\text { Grade } 2\end{array}$ & $\begin{array}{l}\mathrm{FB} \text { and } \mathrm{AF} \text { above } \\
\text { background }\end{array}$ & $\begin{array}{l}\text { Adenocarcinoma } \\
\text { of lung, poorly } \\
\text { differentiated; } \\
\text { metastases to } \\
\text { lymph nodes and } \\
\text { thyroid }\end{array}$ & Unknown \\
\hline 107 & 60 & $\mathrm{~F}$ & Unknown & Unknown & No & No & $\begin{array}{l}\mathrm{P} \\
\text { Grade } 2\end{array}$ & -- & $\begin{array}{l}\text { Adenocarcinoma } \\
\text { of lung, } \\
\text { possible type } \\
\text { II pneumocyte } \\
\text { origin }\end{array}$ & Unknown \\
\hline $\begin{array}{l}167 / \\
\text { U02 }\end{array}$ & 23 & $\mathrm{~F}$ & Unknown & Unknown & Unknown & No & No & -- & $\begin{array}{l}\text { Adenocarcinoma } \\
\text { of lung, } \\
\text { presumably of } \\
\text { pulmonary origin }\end{array}$ & Unknown \\
\hline 108 & 63 & $\mathrm{~F}$ & Unknown & Unknown & No & No & No & -- & $\begin{array}{l}\text { Adenocarcinoma } \\
\text { of lung, probable } \\
\text { Clara cell origin }\end{array}$ & Unknown \\
\hline 109 & 83 & M & Unknown & Unknown & Unknown & $\mathrm{P}$ & No & -- & $\begin{array}{l}\text { Adenocarcinoma } \\
\text { of lung, signet } \\
\text { ring morphology }\end{array}$ & Unknown \\
\hline $\begin{array}{l}170 / \\
\text { U05 }\end{array}$ & 55 & M & 5-pack years & $\begin{array}{l}\text { Boilerman, } \\
\text { pipefitter, } \\
\text { machinist }\end{array}$ & Yes & $\mathrm{P}, \mathrm{R}$ & No & -- & $\begin{array}{l}\text { Adenocarcinoma } \\
\text { of lung, signet } \\
\text { ring morphology }\end{array}$ & 5 months \\
\hline 038 & 60 & M & No & Electrician & Yes & No & $\mathrm{R}$ & -- & $\begin{array}{l}\text { Adenocarcinoma } \\
\text { of lung, signet } \\
\text { ring, mucin } \\
\text { producing }\end{array}$ & 2 months \\
\hline 080 & 71 & M & No & Electrician & Yes & $\mathrm{P}$ & No & -- & $\begin{array}{l}\text { Adenocarcinoma } \\
\text { of lung, tubular } \\
\text { and glandular } \\
\text { differentiation }\end{array}$ & 8 months \\
\hline
\end{tabular}


Hammar et al. Pathology Discovery 2015,

http://www.hoajonline.com/journals/pdf/2052-7896-3-6.pdf

doi: 10.7243/2052-7896-3-6

Continuation of Table 2.

\begin{tabular}{|c|c|c|c|c|c|c|c|c|c|c|}
\hline ID\# & Age & Sex & $\begin{array}{l}\text { Smoking } \\
\text { History }\end{array}$ & $\begin{array}{l}\text { Occupational } \\
\text { History }\end{array}$ & $\begin{array}{l}\text { Asbestos } \\
\text { exposure? }\end{array}$ & $\begin{array}{l}\text { Pleural } \\
\text { plaques }\end{array}$ & $\begin{array}{l}\text { Asbestosis (1982 } \\
\text { CAP-NIOSH) }\end{array}$ & $\begin{array}{l}\text { Ferruginous } \\
\text { bodies OR } \\
\text { Asbestos fibers } \\
\text { (Refer to Table 4) }\end{array}$ & $\begin{array}{l}\text { Pathologic } \\
\text { diagnosis }\end{array}$ & Survival \\
\hline 040 & 74 & $\mathrm{M}$ & Unknown & Unknown & Yes & $\mathrm{P}$ & $\begin{array}{l}\mathrm{P} \\
\text { Grade 1-2 }\end{array}$ & -- & $\begin{array}{l}\text { Adenocarcinoma } \\
\text { of lung, tubular } \\
\text { and glandular } \\
\text { differentiation }\end{array}$ & Unknown \\
\hline 140 & 78 & M & $\begin{array}{l}\text { 5-pack year } \\
\text { maximum }\end{array}$ & Insulator & Yes & No & $\begin{array}{l}\mathrm{P} \\
\text { Grade 3-4 }\end{array}$ & $\begin{array}{l}\text { Iron stains: } \\
\text { Numerous } \\
\text { ferruginous } \\
\text { bodies } \\
\text { characteristic of } \\
\text { asbestos bodies }\end{array}$ & $\begin{array}{l}\text { Adenocarcinoma } \\
\text { of lung, tubular } \\
\text { and glandular } \\
\text { differentiation }\end{array}$ & 1 month \\
\hline 116 & 67 & $\mathrm{M}$ & $\begin{array}{l}1.5-2 \text { packs/ } \\
\text { day; \# of } \\
\text { years un- } \\
\text { known }\end{array}$ & $\begin{array}{l}\text { Digester cooker in } \\
\text { a pulp/paper mill }\end{array}$ & Unknown & No & No & -- & $\begin{array}{l}\text { Adenocarcinoma } \\
\text { of lung, } \\
\text { tubulodesmoplas- } \\
\text { tic type }\end{array}$ & Unknown \\
\hline 119 & 79 & $\mathrm{M}$ & $\begin{array}{l}\text { Yes - } \\
\text { amount not } \\
\text { specified }\end{array}$ & Rancher & Unknown & No & No & -- & $\begin{array}{l}\text { Adenocarcinoma } \\
\text { of lung, tubu- } \\
\text { lodesmoplastic } \\
\text { type }\end{array}$ & Unknown \\
\hline 122 & 42 & $\mathrm{M}$ & Unknown & Unknown & Unknown & No & No & -- & $\begin{array}{l}\text { Adenocarcinoma } \\
\text { of lung, tubu- } \\
\text { lodesmoplastic } \\
\text { type }\end{array}$ & Unknown \\
\hline 121 & 64 & M & Unknown & Unknown & Unknown & No & No & -- & $\begin{array}{l}\text { Adenocarcinoma } \\
\text { of lung, tubu- } \\
\text { lodesmoplastic } \\
\text { type }\end{array}$ & Unknown \\
\hline 113 & 58 & M & No & $\begin{array}{l}\text { Welder at steel } \\
\text { mill }\end{array}$ & Unknown & $\mathrm{P}$ & No & -- & $\begin{array}{l}\text { Adenocarcinoma } \\
\text { of lung, tubu- } \\
\text { lodesmoplastic } \\
\text { type }\end{array}$ & 6 months \\
\hline 114 & 54 & $\mathrm{M}$ & Unknown & Unknown & Unknown & No & No & $\begin{array}{l}\text { FB above } \\
\text { background }\end{array}$ & $\begin{array}{l}\text { Adenocarcinoma } \\
\text { of lung, tubu- } \\
\text { lodesmoplastic } \\
\text { type }\end{array}$ & Unknown \\
\hline 120 & 74 & M & Unknown & Unknown & Unknown & $\mathrm{P}$ & $\begin{array}{l}\mathrm{P} \\
\text { Grade 2-3 }\end{array}$ & $\begin{array}{l}\text { Iron stains: } 11 \\
\text { ferruginous } \\
\text { bodies } \\
\text { characteristic of } \\
\text { asbestos bodies }\end{array}$ & $\begin{array}{l}\text { Adenocarcinoma } \\
\text { of lung, tubu- } \\
\text { lodesmoplastic } \\
\text { type }\end{array}$ & Unknown \\
\hline 117 & 65 & M & $\begin{array}{l}22.5 \text {-pack } \\
\text { years }\end{array}$ & Foundry worker & Yes & No & No & -- & $\begin{array}{l}\text { Adenocarcinoma } \\
\text { of lung, tubu- } \\
\text { lodesmoplastic } \\
\text { type }\end{array}$ & Unknown \\
\hline 115 & 41 & $\mathrm{M}$ & $\begin{array}{l}\text { 33-pack } \\
\text { years }\end{array}$ & $\begin{array}{l}\text { Machinist, brake } \\
\text { and clutch work } \\
\text { on personal } \\
\text { vehicles }\end{array}$ & Yes & No & No & -- & $\begin{array}{l}\text { Adenocarcinoma } \\
\text { of lung, tubu- } \\
\text { lodesmoplastic } \\
\text { type }\end{array}$ & Unknown \\
\hline 111 & 69 & M & $\begin{array}{l}75 \text {-pack } \\
\text { years }\end{array}$ & $\begin{array}{l}\text { Boilermaker, } \\
\text { welder }\end{array}$ & Yes & No & No & -- & $\begin{array}{l}\text { Adenocarcinoma } \\
\text { of lung, tubu- } \\
\text { lodesmoplastic } \\
\text { type }\end{array}$ & 5 months \\
\hline 123 & 66 & $\mathrm{M}$ & No & $\begin{array}{l}\text { Marine machinist, } \\
\text { railroad brakeman }\end{array}$ & Yes & $\mathrm{P}$ & No & $\begin{array}{l}\text { AF above } \\
\text { background }\end{array}$ & $\begin{array}{l}\text { Adenocarcinoma } \\
\text { of lung, tubu- } \\
\text { lodesmoplastic } \\
\text { type }\end{array}$ & 6 months \\
\hline 118 & 73 & M & $\begin{array}{l}\text { Yes - } \\
\text { amount not } \\
\text { specified }\end{array}$ & $\begin{array}{l}\text { Shipyard worker } \\
\text { and in U.S. Navy } \\
\text { - exposed to } \\
\text { gaskets, packing, } \\
\text { refractories, boil- } \\
\text { ers, pumps, etc. }\end{array}$ & Yes & No & No & $\begin{array}{l}\text { FB above back- } \\
\text { ground; } 3 \mathrm{AB} \\
\text { in iron stained } \\
\text { sections }\end{array}$ & $\begin{array}{l}\text { Adenocarcinoma } \\
\text { of lung, tubu- } \\
\text { lodesmoplastic } \\
\text { type }\end{array}$ & Unknown \\
\hline
\end{tabular}


Hammar et al. Pathology Discovery 2015,

http://www.hoajonline.com/journals/pdf/2052-7896-3-6.pdf

doi: $10.7243 / 2052-7896-3-6$

Continuation of Table 2.

\begin{tabular}{|c|c|c|c|c|c|c|c|c|c|c|}
\hline ID\# & Age & Sex & $\begin{array}{l}\text { Smoking } \\
\text { History }\end{array}$ & $\begin{array}{l}\text { Occupational } \\
\text { History }\end{array}$ & $\begin{array}{l}\text { Asbestos } \\
\text { exposure? }\end{array}$ & $\begin{array}{l}\text { Pleural } \\
\text { plaques }\end{array}$ & $\begin{array}{l}\text { Asbestosis (1982 } \\
\text { CAP-NIOSH) }\end{array}$ & $\begin{array}{l}\text { Ferruginous } \\
\text { bodies OR } \\
\text { Asbestos fibers } \\
\text { (Refer to Table 4) }\end{array}$ & $\begin{array}{l}\text { Pathologic } \\
\text { diagnosis }\end{array}$ & Survival \\
\hline $\begin{array}{l}153 / \\
\text { FA08 }\end{array}$ & 61 & $\mathrm{M}$ & $\begin{array}{l}20 \text { to } 54- \\
\text { pack years }\end{array}$ & $\begin{array}{l}\text { Electrician in U.S. } \\
\text { Navy ( } 20 \text { years) }\end{array}$ & Yes & No & No & $\begin{array}{l}\mathrm{FB} \text { and } \mathrm{AF} \text { above } \\
\text { background }\end{array}$ & $\begin{array}{l}\text { Adenocarcinoma } \\
\text { of lung, tubu- } \\
\text { lodesmoplastic } \\
\text { type; metastases } \\
\text { to liver, adrenal, } \\
\text { and lymph nodes }\end{array}$ & 6 months \\
\hline $\begin{array}{l}156 / \\
\text { FA11 }\end{array}$ & $\mathrm{U}$ & $\mathrm{M}$ & Unknown & Unknown & Unknown & No & No & $\begin{array}{l}\mathrm{FB} \text { and } \mathrm{AF} \text { above } \\
\text { background }\end{array}$ & $\begin{array}{l}\text { Adenocarcinoma } \\
\text { of lung, tubu- } \\
\text { lodesmoplastic } \\
\text { type; metastasis } \\
\text { to liver }\end{array}$ & Unknown \\
\hline 126 & 72 & $\mathrm{M}$ & No & $\begin{array}{l}\text { Coppersmith, } \\
\text { oiler, wiper, fire- } \\
\text { man, water tender }\end{array}$ & Yes & No & No & -- & $\begin{array}{l}\text { Adenocarcinoma } \\
\text { of lung, } \\
\text { tubulopapillary } \\
\text { type }\end{array}$ & Unknown \\
\hline 124 & 76 & $\mathrm{M}$ & $\begin{array}{l}\text { No (smoked } \\
\text { a pipe) }\end{array}$ & $\begin{array}{l}\text { Refinery worker/ } \\
\text { laborer; paraoccu- } \\
\text { pational exposure } \\
\text { from father who } \\
\text { was a boilermaker }\end{array}$ & Yes & $\mathrm{P}$ & No & -- & $\begin{array}{l}\text { Adenocarcinoma } \\
\text { of lung, } \\
\text { tubulopapillary } \\
\text { type }\end{array}$ & 7 months \\
\hline 125 & 63 & M & $\begin{array}{l}40 \text { to } 61- \\
\text { pack years }\end{array}$ & Electrician & Yes & No & $\mathrm{R}$ & -- & $\begin{array}{l}\text { Adenocarcinoma } \\
\text { of lung, tubulo- } \\
\text { papillary/ } \\
\text { glandular type }\end{array}$ & 11 months \\
\hline 131 & 78 & $\mathrm{M}$ & Unknown & Unknown & Unknown & No & No & -- & $\begin{array}{l}\text { Adenosquamous } \\
\text { carcinoma of lung }\end{array}$ & Unknown \\
\hline 129 & 74 & $\mathrm{M}$ & $\begin{array}{l}15 \text {-pack } \\
\text { years }\end{array}$ & Unknown & Unknown & No & $\begin{array}{l}\mathrm{P} \\
\text { Grade 1-2 }\end{array}$ & -- & $\begin{array}{l}\text { Adenosquamous } \\
\text { carcinoma of lung }\end{array}$ & 9 months \\
\hline 128 & 62 & $\mathrm{M}$ & Unknown & Unknown & Unknown & $\mathrm{P}$ & No & $\begin{array}{l}\text { FB above } \\
\text { background }\end{array}$ & $\begin{array}{l}\text { Adenosquamous } \\
\text { carcinoma of lung }\end{array}$ & Unknown \\
\hline 127 & 80 & $\mathrm{M}$ & Unknown & Unknown & Unknown & $\mathrm{P}$ & $\begin{array}{l}\mathrm{P} \\
\text { Grade 1-2 }\end{array}$ & $\begin{array}{l}\text { FB above } \\
\text { background }\end{array}$ & $\begin{array}{l}\text { Adenosquamous } \\
\text { carcinoma of lung }\end{array}$ & Unknown \\
\hline $\begin{array}{l}147 / \\
\text { FA02 }\end{array}$ & 74 & $\mathrm{M}$ & $\begin{array}{l}40 \text {-pack } \\
\text { years }\end{array}$ & $\begin{array}{l}\text { Shipyard worker } \\
\text { (29 years) }\end{array}$ & Yes & $\mathrm{P}, \mathrm{R}$ & $\begin{array}{l}\mathrm{P} \\
\text { Grade 3-4 }\end{array}$ & $\begin{array}{l}\mathrm{FB} \text { and } \mathrm{AF} \text { above } \\
\text { background }\end{array}$ & $\begin{array}{l}\text { Adenosquamous } \\
\text { carcinoma of lung }\end{array}$ & 19 months \\
\hline 145 & 70 & $\mathrm{M}$ & $\begin{array}{l}\text { 102-pack } \\
\text { years }\end{array}$ & $\begin{array}{l}\text { Shipfitter, steamfit- } \\
\text { ter }\end{array}$ & Yes & $\mathrm{P}, \mathrm{R}$ & $\begin{array}{l}\mathrm{P} \\
\text { Grade } 2\end{array}$ & $\begin{array}{l}\text { Iron stains: } 43 \\
\text { ferruginous } \\
\text { bodies } \\
\text { characteristic of } \\
\text { asbestos bodies }\end{array}$ & $\begin{array}{l}\text { Adenosquamous } \\
\text { carcinoma of lung }\end{array}$ & 7 months \\
\hline 130 & 58 & M & Unknown & $\begin{array}{l}\text { Laborer, pipefitter, } \\
\text { welder, plumber }\end{array}$ & Yes & $\mathrm{P}$ & $\begin{array}{l}\mathrm{P} \\
\text { Grade } 4\end{array}$ & $\begin{array}{l}\text { Iron stains: } \\
\text { Several } \\
\text { ferruginous } \\
\text { bodies } \\
\text { characteristic of } \\
\text { asbestos bodies }\end{array}$ & $\begin{array}{l}\text { Adenosquamous } \\
\text { carcinoma of lung }\end{array}$ & Unknown \\
\hline $\begin{array}{l}\text { 160/ } \\
\text { FA15 }\end{array}$ & 67 & M & Unknown & $\begin{array}{l}\text { Shipyard worker } \\
\text { ( } 3 \text { years); boat- } \\
\text { swains mate ( } 9 \\
\text { years) }\end{array}$ & Unknown & $\mathrm{P}$ & No & $\begin{array}{l}\text { FB below } \\
\text { background; AF } \\
\text { above background }\end{array}$ & $\begin{array}{l}\text { Adenosquamous } \\
\text { carcinoma of } \\
\text { lung, poorly } \\
\text { differentiated; } \\
\text { metastasis to liver }\end{array}$ & 2 months \\
\hline 132 & 60 & $\mathrm{M}$ & Unknown & $\begin{array}{l}\text { Mechanic/mainte- } \\
\text { nance man }\end{array}$ & Yes & No & No & $\begin{array}{l}\text { FB above } \\
\text { background }\end{array}$ & $\begin{array}{l}\text { Adenosquamous } \\
\text { carcinoma of } \\
\text { lung, poorly- } \\
\text { differentiated }\end{array}$ & 4 months \\
\hline $\begin{array}{l}171 / \\
\text { U06 }\end{array}$ & 59 & $\mathrm{M}$ & $\begin{array}{l}60 \text {-pack } \\
\text { years }\end{array}$ & $\begin{array}{l}\text { Inspector for gas } \\
\text { company }\end{array}$ & Yes & $\mathrm{P}$ & No & -- & $\begin{array}{l}\text { Basaloid } \\
\text { carcinoma }\end{array}$ & $\begin{array}{l}<3 \\
\text { months }\end{array}$ \\
\hline
\end{tabular}


Hammar et al. Pathology Discovery 2015,

http://www.hoajonline.com/journals/pdf/2052-7896-3-6.pdf

doi: 10.7243/2052-7896-3-6

\section{Continuation of Table 2.}

\begin{tabular}{|c|c|c|c|c|c|c|c|c|c|c|}
\hline ID\# & Age & Sex & $\begin{array}{l}\text { Smoking } \\
\text { History }\end{array}$ & $\begin{array}{l}\text { Occupational } \\
\text { History }\end{array}$ & $\begin{array}{l}\text { Asbestos } \\
\text { exposure? }\end{array}$ & $\begin{array}{l}\text { Pleural } \\
\text { plaques }\end{array}$ & $\begin{array}{l}\text { Asbestosis (1982 } \\
\text { CAP-NIOSH) }\end{array}$ & $\begin{array}{l}\text { Ferruginous } \\
\text { bodies OR } \\
\text { Asbestos fibers } \\
\text { (Refer to Table 4) }\end{array}$ & $\begin{array}{l}\text { Pathologic } \\
\text { diagnosis }\end{array}$ & Survival \\
\hline 134 & 74 & $\mathrm{M}$ & $\begin{array}{l}\text { Yes - } \\
\text { amount not } \\
\text { specified }\end{array}$ & Unknown & Yes & $\mathrm{P}$ & $\begin{array}{l}\mathrm{P} \\
\text { Grade } 3\end{array}$ & $\begin{array}{l}\text { FB above back- } \\
\text { ground }\end{array}$ & $\begin{array}{l}\text { Bronchioloalveo- } \\
\text { lar cell carcinoma }\end{array}$ & Unknown \\
\hline 133 & 61 & M & $\begin{array}{l}44 \text {-pack } \\
\text { years }\end{array}$ & Boilerman & Yes & $\mathrm{P}$ & $\begin{array}{l}\mathrm{P} \\
\text { Grade } 4\end{array}$ & $\begin{array}{l}\text { FB below back- } \\
\text { ground }\end{array}$ & $\begin{array}{l}\text { Bronchioloalveo- } \\
\text { lar cell carcinoma }\end{array}$ & Unknown \\
\hline $\begin{array}{l}172 / \\
\text { U07 }\end{array}$ & 43 & M & Unknown & Unknown & Unknown & No & No & -- & $\begin{array}{l}\text { Calcifying fibrous } \\
\text { tumor of the } \\
\text { pleura }\end{array}$ & Unknown \\
\hline $\begin{array}{l}175 / \\
\mathrm{U} 10\end{array}$ & 67 & M & $\begin{array}{l}\text { Yes - } \\
\text { amount not } \\
\text { specified }\end{array}$ & $\begin{array}{l}\text { Worked with } \\
\text { industrial solvents } \\
\text { and chemicals } \\
\text { used for tanning } \\
\text { hides }\end{array}$ & No & No & No & -- & $\begin{array}{l}\text { Sarcomatoid } \\
\text { carcinoma }\end{array}$ & Unknown \\
\hline $\begin{array}{l}174 / \\
\text { U09 }\end{array}$ & 81 & M & Unknown & Unknown & Unknown & $\mathrm{P}$ & No & -- & $\begin{array}{l}\text { Sarcomatoid } \\
\text { carcinoma }\end{array}$ & Unknown \\
\hline $\begin{array}{l}173 / \\
\text { U08 }\end{array}$ & 68 & M & $\begin{array}{l}\text { Yes - } \\
\text { amount not } \\
\text { specified }\end{array}$ & Driller in shipyard & Yes & $\mathrm{P}$ & No & $\begin{array}{l}\text { FB above } \\
\text { background }\end{array}$ & $\begin{array}{l}\text { Sarcomatoid } \\
\text { carcinoma }\end{array}$ & 11 months \\
\hline 137 & 69 & M & No & $\begin{array}{l}\text { Carpenter/Joiner } \\
\text { at boatbuilding } \\
\text { company }\end{array}$ & Yes & $\mathrm{P}$ & No & $\begin{array}{l}\text { FB above } \\
\text { background }\end{array}$ & $\begin{array}{l}\text { Sarcomatoid } \\
\text { carcinoma }\end{array}$ & 4 months \\
\hline 136 & 76 & M & $\begin{array}{l}120 \text {-pack } \\
\text { years }\end{array}$ & Insulator & Yes & $\mathrm{P}, \mathrm{R}$ & $\begin{array}{l}\mathrm{P} \\
\text { Grade } 4\end{array}$ & $\begin{array}{l}\text { FB above } \\
\text { background }\end{array}$ & $\begin{array}{l}\text { Sarcomatoid } \\
\text { carcinoma }\end{array}$ & Unknown \\
\hline $\begin{array}{l}176 / \\
\mathrm{U} 11\end{array}$ & 80 & M & $\begin{array}{l}12 \text {-pack } \\
\text { years }\end{array}$ & $\begin{array}{l}\text { Steamfitter, pip- } \\
\text { efitter }\end{array}$ & Yes & $\mathrm{P}, \mathrm{R}$ & $\begin{array}{l}\mathrm{P} \\
\text { Grade } 2\end{array}$ & $\begin{array}{l}\text { Iron stains: } 182 \\
\text { ferruginous } \\
\text { bodies } \\
\text { characteristic of } \\
\text { asbestos bodies in } \\
5.7 \text { sq. cm. or } 31.9 \\
\text { AB per sq. cm. of } \\
\text { lung tissue }\end{array}$ & $\begin{array}{l}\text { Sarcomatoid } \\
\text { carcinoma }\end{array}$ & 4 months \\
\hline $\begin{array}{l}186 / \\
\mathrm{U} 21\end{array}$ & 60 & M & $\begin{array}{l}11.5 \text {-pack } \\
\text { years }\end{array}$ & $\begin{array}{l}\text { Electrician, electri- } \\
\text { cal engineer, pro- } \\
\text { duction engineer, } \\
\text { general manager }\end{array}$ & Yes & $\mathrm{R}$ & No & $\begin{array}{l}\text { Iron stains: No } \\
\text { ferruginous } \\
\text { bodies }\end{array}$ & $\begin{array}{l}\text { Combined } \\
\text { pseudo-meso- } \\
\text { theliomatous } \\
\text { adenocarcinoma } \\
\text { of lung; and a } \\
\text { poorly differenti- } \\
\text { ated basaloid } \\
\text { squamous cell } \\
\text { carcinoma arising } \\
\text { from the sino- } \\
\text { nasal region that } \\
\text { was metastatic to } \\
\text { the liver and skull }\end{array}$ & 6 years \\
\hline $\begin{array}{l}189 / \\
\mathrm{U} 24\end{array}$ & 67 & M & Unknown & $\begin{array}{l}\text { Sheet metal } \\
\text { worker }\end{array}$ & Yes & $\mathrm{P}$ & No & $\begin{array}{l}\text { FB above back- } \\
\text { ground }\end{array}$ & $\begin{array}{l}\text { Combined } \\
\text { pseudo-meso- } \\
\text { theliomatous } \\
\text { mucin-producing } \\
\text { adenocarcinoma } \\
\text { of the lung and a } \\
\text { biphasic } \\
\text { mesothelioma }\end{array}$ & 3 months \\
\hline $\begin{array}{l}178 / \\
\mathrm{U} 13\end{array}$ & 59 & M & Unknown & $\begin{array}{l}\text { Crew boat captain, } \\
\text { welder, commer- } \\
\text { cial fisherman }\end{array}$ & Unknown & No & No & $\begin{array}{l}\text { Iron stains: No } \\
\text { ferruginous } \\
\text { bodies }\end{array}$ & $\begin{array}{l}\text { Combined } \\
\text { pseudo-mesothe- } \\
\text { liomatous small } \\
\text { cell adenocarci- } \\
\text { noma or small } \\
\text { cell squamous } \\
\text { cell carcinoma \& } \\
\text { pleural mesothe- } \\
\text { lioma }\end{array}$ & Unknown \\
\hline
\end{tabular}


Hammar et al. Pathology Discovery 2015,

Continuation of Table 2.

\begin{tabular}{|c|c|c|c|c|c|c|c|c|c|c|}
\hline ID\# & Age & Sex & $\begin{array}{l}\text { Smoking } \\
\text { History }\end{array}$ & $\begin{array}{l}\text { Occupational } \\
\text { History }\end{array}$ & $\begin{array}{l}\text { Asbestos } \\
\text { exposure? }\end{array}$ & $\begin{array}{l}\text { Pleural } \\
\text { plaques }\end{array}$ & $\begin{array}{l}\text { Asbestosis (1982 } \\
\text { CAP-NIOSH) }\end{array}$ & $\begin{array}{l}\text { Ferruginous } \\
\text { bodies OR } \\
\text { Asbestos fibers } \\
\text { (Refer to Table 4) }\end{array}$ & $\begin{array}{l}\text { Pathologic } \\
\text { diagnosis }\end{array}$ & Survival \\
\hline $\begin{array}{l}177 / \\
\mathrm{U} 12\end{array}$ & 67 & $\mathrm{M}$ & $\begin{array}{l}20.5 \text { to } 41- \\
\text { pack years }\end{array}$ & $\begin{array}{l}\text { Automotive } \\
\text { mechanic, laborer, } \\
\text { welder, carpenter }\end{array}$ & Yes & $\mathrm{R}$ & $\begin{array}{l}\mathrm{R} \\
\text { (probable) }\end{array}$ & $\begin{array}{l}\text { Iron stains: } 01 \\
\text { ferruginous body } \\
\text { characteristic of } \\
\text { an asbestos body }\end{array}$ & $\begin{array}{l}\text { Combined } \\
\text { pseudo-meso- } \\
\text { theliomatous } \\
\text { small cell lung } \\
\text { cancer and poorly } \\
\text { differentiated } \\
\text { adenocarcinoma }\end{array}$ & 10 months \\
\hline $\begin{array}{l}181 / \\
\mathrm{U} 16\end{array}$ & 38 & $\mathrm{~F}$ & Unknown & Unknown & No & No & No & -- & $\begin{array}{l}\text { Hemangio- } \\
\text { endothelioma, left } \\
\text { pleural }\end{array}$ & Unknown \\
\hline $\begin{array}{l}180 / \\
\mathrm{U} 15\end{array}$ & 59 & $\mathrm{~F}$ & No & $\begin{array}{l}\text { Lab Technician in } \\
\text { healthcare field }\end{array}$ & Unknown & No & No & -- & $\begin{array}{l}\text { Hemangio-endo- } \\
\text { thelioma, right } \\
\text { pleural }\end{array}$ & 10 months \\
\hline $\begin{array}{l}179 / \\
\mathrm{U} 14\end{array}$ & 51 & $\mathrm{M}$ & No & $\begin{array}{l}\text { Hardware store } \\
\text { cutting asbestos } \\
\text { board }\end{array}$ & Yes & No & No & -- & $\begin{array}{l}\text { Hemangio-endo- } \\
\text { thelioma, right } \\
\text { pleural }\end{array}$ & Unknown \\
\hline $\begin{array}{l}182 / \\
\mathrm{U} 17\end{array}$ & 80 & $\mathrm{M}$ & $\begin{array}{l}17 \text {-pack } \\
\text { years }\end{array}$ & $\begin{array}{l}\text { Motor inspector } \\
\text { and steelworker } \\
\text { at steel plant for } \\
\text { approximately } 35 \\
\text { years }\end{array}$ & Yes & No & No & -- & $\begin{array}{l}\text { Hemangio-endo- } \\
\text { thelioma, right } \\
\text { pleural }\end{array}$ & 3 months \\
\hline $\begin{array}{l}197 / \\
\text { U32 }\end{array}$ & 70 & $\mathrm{M}$ & Unknown & Plumber & Yes & $\mathrm{P}$ & No & $\begin{array}{l}\text { Iron stains: No } \\
\text { ferruginous } \\
\text { bodies }\end{array}$ & $\begin{array}{l}\text { Metastatic } \\
\text { pseudo-meso- } \\
\text { theliomatous } \\
\text { adenosquamous } \\
\text { cell carcinoma } \\
\text { involving right } \\
\text { pleura; metastatic } \\
\text { from mouth }\end{array}$ & Unknown \\
\hline $\begin{array}{l}183 / \\
\mathrm{U} 18\end{array}$ & 70 & $\mathrm{M}$ & Unknown & Unknown & No & No & No & -- & $\begin{array}{l}\text { Metastatic } \\
\text { pseudo-meso- } \\
\text { theliomatous } \\
\text { melanoma to the } \\
\text { left lung/pleura }\end{array}$ & 7 months \\
\hline $\begin{array}{l}184 / \\
\text { U19 }\end{array}$ & 50 & $\mathrm{M}$ & Unknown & Painter & Unknown & No & No & -- & $\begin{array}{l}\text { Metastatic } \\
\text { pseudo-meso- } \\
\text { theliomatous } \\
\text { melanoma to the } \\
\text { right lung/pleura }\end{array}$ & Unknown \\
\hline $\begin{array}{l}185 / \\
\mathrm{U} 20\end{array}$ & 82 & M & No & Carpenter & Yes & $\mathrm{P}$ & No & -- & $\begin{array}{l}\text { Metastatic } \\
\text { pseudo-meso- } \\
\text { theliomatous } \\
\text { melanoma to the } \\
\text { right lung/pleura }\end{array}$ & 2 months \\
\hline $\begin{array}{l}187 / \\
\mathrm{U} 22\end{array}$ & 68 & $\mathrm{M}$ & Unknown & Unknown & Unknown & No & No & -- & $\begin{array}{l}\text { Metastatic pseu- } \\
\text { do-mesothelio- } \\
\text { matous squamous } \\
\text { cell carcinoma of } \\
\text { lung; metastatic } \\
\text { from tongue }\end{array}$ & Unknown \\
\hline $\begin{array}{l}193 / \\
\mathrm{U} 28\end{array}$ & 60 & $\mathrm{M}$ & Unknown & Unknown & Unknown & $\mathrm{P}$ & No & -- & $\begin{array}{l}\text { Metastatic renal } \\
\text { cell carcinoma, } \\
\text { left, clear cell } \\
\text { type; metastatic } \\
\text { to pleura }\end{array}$ & 4 months \\
\hline $\begin{array}{l}191 / \\
\mathrm{U} 26\end{array}$ & 64 & $\mathrm{M}$ & Unknown & Unknown & Unknown & No & No & -- & $\begin{array}{l}\text { Metastatic renal } \\
\text { cell carcinoma, } \\
\text { left, papillary; } \\
\text { metastatic to } \\
\text { pleura }\end{array}$ & Unknown \\
\hline
\end{tabular}


Hammar et al. Pathology Discovery 2015,

http://www.hoajonline.com/journals/pdf/2052-7896-3-6.pdf

doi: $10.7243 / 2052-7896-3-6$

Continuation of Table 2 .

\begin{tabular}{|c|c|c|c|c|c|c|c|c|c|c|}
\hline ID\# & Age & Sex & $\begin{array}{l}\text { Smoking } \\
\text { History }\end{array}$ & $\begin{array}{l}\text { Occupational } \\
\text { History }\end{array}$ & $\begin{array}{l}\text { Asbestos } \\
\text { exposure? }\end{array}$ & $\begin{array}{l}\text { Pleural } \\
\text { plaques }\end{array}$ & $\begin{array}{l}\text { Asbestosis (1982 } \\
\text { CAP-NIOSH) }\end{array}$ & $\begin{array}{l}\text { Ferruginous } \\
\text { bodies OR } \\
\text { Asbestos fibers } \\
\text { (Refer to Table 4) }\end{array}$ & $\begin{array}{l}\text { Pathologic } \\
\text { diagnosis }\end{array}$ & Survival \\
\hline $\begin{array}{l}190 / \\
\mathrm{U} 25\end{array}$ & 69 & $\mathrm{M}$ & Unknown & $\begin{array}{l}\text { Pipefitter at paper } \\
\text { mill }\end{array}$ & Yes & $\mathrm{P}$ & No & $\begin{array}{l}\text { Iron stains: } 34 \text { fer- } \\
\text { ruginous bodies } \\
\text { characteristic of } \\
\text { asbestos bodies }\end{array}$ & $\begin{array}{l}\text { Metastatic renal } \\
\text { cell carcinoma, } \\
\text { left, poorly } \\
\text { differentiated; } \\
\text { metastases to R. } \\
\text { lung, omentum, } \\
\text { and adrenal gland }\end{array}$ & 2 months \\
\hline $\begin{array}{l}192 / \\
\mathrm{U} 27\end{array}$ & 41 & $\mathrm{M}$ & Unknown & $\begin{array}{l}\text { Maintenance man, } \\
\text { including painting, } \\
\text { drywall and lino- } \\
\text { leum installation, } \\
\text { and general repairs }\end{array}$ & Yes & No & No & $\begin{array}{l}\text { Iron stains: No } \\
\text { ferruginous } \\
\text { bodies }\end{array}$ & $\begin{array}{l}\text { Metastatic renal } \\
\text { cell carcinoma, } \\
\text { left; metastases } \\
\text { to both lungs and } \\
\text { pleura }\end{array}$ & 3 months \\
\hline 138 & 61 & $\mathrm{M}$ & $\begin{array}{l}50 \text {-pack } \\
\text { years }\end{array}$ & Unknown & Unknown & No & No & -- & $\begin{array}{l}\text { Non-small cell } \\
\text { carcinoma of lung }\end{array}$ & Unknown \\
\hline 139 & 65 & $\mathrm{M}$ & $\begin{array}{l}80 \text {-pack } \\
\text { years }\end{array}$ & Insulator & Yes & $\mathrm{P}$ & No & $\begin{array}{l}\text { Iron stains: } \\
\text { Numerous fer- } \\
\text { ruginous bodies } \\
\text { characteristic of } \\
\text { asbestos bodies }\end{array}$ & $\begin{array}{l}\text { Non-small cell } \\
\text { carcinoma of lung }\end{array}$ & 4 months \\
\hline 019 & 77 & $\mathrm{M}$ & No & $\begin{array}{l}\text { U.S. Army, } \\
\text { custodian, lab } \\
\text { technician }\end{array}$ & Yes & $\mathrm{P}$ & No & -- & $\begin{array}{l}\text { Peritoneal } \\
\text { adenocarcinoma, } \\
\text { mucin producing }\end{array}$ & 8 months \\
\hline $\begin{array}{l}168 / \\
\text { U03 }\end{array}$ & 70 & $\mathrm{~F}$ & Unknown & Unknown & Unknown & No & No & -- & $\begin{array}{l}\text { Peritoneal } \\
\text { adenocarcinoma, } \\
\text { Mullerian origin }\end{array}$ & 2 months \\
\hline $\begin{array}{l}195 / \\
\text { U30 }\end{array}$ & 82 & $\mathrm{~F}$ & $\begin{array}{l}60 \text { to } 120- \\
\text { pack years }\end{array}$ & Painter & Bystander & No & No & -- & $\begin{array}{l}\text { Small cell lung } \\
\text { cancer }\end{array}$ & 3 months \\
\hline $\begin{array}{l}196 / \\
\mathrm{U} 31\end{array}$ & 70 & $\mathrm{~F}$ & Unknown & Unknown & Unknown & No & No & -- & $\begin{array}{l}\text { Small cell lung } \\
\text { cancer }\end{array}$ & Unknown \\
\hline $\begin{array}{l}194 / \\
\text { U29 }\end{array}$ & 84 & $\mathrm{M}$ & $\begin{array}{l}30 \text {-pack } \\
\text { years }\end{array}$ & Welder, mechanic & Yes & $\mathrm{P}, \mathrm{R}$ & $\begin{array}{l}\mathrm{P} \\
\text { Grade 3-4 }\end{array}$ & -- & $\begin{array}{l}\text { Small cell lung } \\
\text { cancer }\end{array}$ & 2 months \\
\hline 143 & 58 & M & No & $\begin{array}{l}\text { Building mainte- } \\
\text { nance }\end{array}$ & Yes & No & No & -- & $\begin{array}{l}\text { Squamous cell } \\
\text { carcinoma of lung }\end{array}$ & $3+$ years \\
\hline 141 & 83 & M & $\begin{array}{l}48 \text {-pack } \\
\text { years }\end{array}$ & $\begin{array}{l}\text { Construction } \\
\text { worker }\end{array}$ & Yes & $\mathrm{P}, \mathrm{R}$ & No & -- & $\begin{array}{l}\text { Squamous cell } \\
\text { carcinoma of lung }\end{array}$ & 1 month \\
\hline 144 & 82 & M & $\begin{array}{l}150 \text {-pack } \\
\text { years }\end{array}$ & Welder & Yes & $\mathrm{R}$ & No & -- & $\begin{array}{l}\text { Squamous cell } \\
\text { carcinoma of lung }\end{array}$ & Unknown \\
\hline 142 & 80 & $\mathrm{M}$ & $\begin{array}{l}5 \text { to } 10 \text {-pack } \\
\text { years }\end{array}$ & $\begin{array}{l}\text { Boilermaker, } \\
\text { welder }\end{array}$ & Yes & $\mathrm{R}$ & $\begin{array}{l}\mathrm{P} \\
\text { Grade } 4\end{array}$ & $\begin{array}{l}\text { FB above } \\
\text { background }\end{array}$ & $\begin{array}{l}\text { Squamous cell } \\
\text { carcinoma of lung }\end{array}$ & 1 month \\
\hline $\begin{array}{l}162 / \\
\text { FA17 }\end{array}$ & 77 & M & Unknown & Unknown & Unknown & No & No & $\begin{array}{l}\mathrm{FB} \text { and } \mathrm{AF} \text { above } \\
\text { background }\end{array}$ & $\begin{array}{l}\text { Squamous cell } \\
\text { carcinoma of } \\
\text { lung; metastases } \\
\text { to lymph nodes }\end{array}$ & Unknown \\
\hline $\begin{array}{l}188 / \\
\mathrm{U} 23\end{array}$ & 79 & M & $\begin{array}{l}30 \text {-pack } \\
\text { years }\end{array}$ & $\begin{array}{l}\text { Automotive } \\
\text { mechanic }\end{array}$ & Yes & $\mathrm{P}$ & No & -- & $\begin{array}{l}\text { Squamous cell } \\
\text { carcinoma, either } \\
\text { lung primary or } \\
\text { metastatic from } \\
\text { larynx (note: } \\
\text { status-post total } \\
\text { laryngectomy } \\
\text { for squamous } \\
\text { cell carcinoma of } \\
\text { larynx diagnosed } \\
\text { in 1990) }\end{array}$ & Unknown \\
\hline
\end{tabular}

Key: U: Unknown; M: Male; F: Female; P: Pathologic; R: Radiographic; FB: Ferruginous bodies; AB: Asbestos bodies; AF: Asbestos fibers 
Hammar et al. Pathology Discovery 2015,

Table 3. Histologic types of 196 pseudomesotheliomatous carcinomas.

Adenocarcinoma: 150

Squamous cell carcinoma: 5

Adenosquamous (combined adenocarcinoma and squamous cell

carcinoma): 9

Large cell undifferentiated: 0

Small cell lung cancer: 3

\section{Unusual Pseudomesotheliomatous Carcinomas:}

1 Adenocarcinoma of lung, mucin producing, probable Mullerian origin

1 Basaloid carcinoma

1 Calcifying fibrous pseudotumor

1 Combined adenocarcinoma of lung and biphasic mesothelioma

1 Combined adenocarcinoma of lung and basaloid squamous cell

carcinoma arising from the sino-nasal region that was metastatic to the

liver and skull

1 Combined small cell lung cancer and poorly differentiated

adenocarcinoma

1 Combined small cell adenocarcinoma or small cell squamous cell

carcinoma \& mesothelioma

4 Hemangioendotheliomas

1 Metastatic adenosquamous cell carcinoma from mouth

3 Metastatic melanomas

4 Metastatic renal cell carcinomas

1 Metastatic squamous cell carcinoma from tongue

6 Sarcomatoid carcinomas

1 Squamous cell carcinoma, either lung primary or metastatic from larynx 2 Peritoneal adenocarcinomas (cases \#19 and \#168)

\section{Discussion}

Pseudomesotheliomatous lung cancers are rare neoplasms, most of which are primary pulmonary carcinomas that macroscopically grow like diffuse pleural mesotheliomas. Some insist that only tumors growing in a pleural distribution in which there are no primary lung masses (tumors) be included as pseudomesotheliomas, although others would accept cases where the tumor is growing predominantly in a pleural distribution in which a mass in the lung exists which may be the source of the predominantly pleural tumor.

The most frequent forms of adenocarcinoma are mucinproducing, tubulodesmoplastic, acinar, and poorly differentiated. Less common adenocarcinomas include signet ring adenocarcinoma, adenocarcinoma of type 2 pneumocyte origin, and adenocarcinoma with a papillary/micropapillary morphology. Other primary carcinomas involving the lung and which may grow like a diffuse pleural mesothelioma include adenosquamous carcinoma, squamous cell carcinoma, deciduoid carcinoma, and rhabdoid carcinoma. Other rare/ unusual types of neoplasms that grow in a diffuse pleural distribution include metastatic melanoma, calcifying fibrous tumors of the pleura, small cell lung cancer, hemangioendothelioma, metastatic renal cell carcinoma, sarcomatoid carcinoma, basaloid carcinoma, and metastatic squamous cell carcinomas from the larynx and mouth, as well as combined adenocarcinomas and mesothelioma.

The primary differential diagnosis of pseudomesotheliomatous lung cancers include epithelial mesothelioma, sarcomatoid mesothelioma (sarcomatoid cases), and biphasic sarcomatoid mesothelioma. Also in the differential diagnosis is metastatic carcinoma from a site outside the chest and rare sarcomas that grow in a pleural distribution, such as synovial sarcomas. As shown in our report, the majority of pseudomesotheliomatous cancers are primary lung cancers; specifically, adenocarcinomas. Just as there is a wide range of variation of primary adenocarcinomas of the lung, there is also a wide variation of pseudomesotheliomatous adenocarcinomas of the lung. Pseudomesotheliomatous lung cancers can also metastasize to other parts of the body, including regional lymph nodes, opposite lung, liver, bone, and brain.

Pseudomesotheliomatous lung cancers usually present with the same signs and symptoms as diffuse pleural mesothelioma. Pleural effusions are common in both pseudomesotheliomatous lung cancers and pleural mesotheliomas. Pleural fluid can be evaluated for malignant cells using cytologic, histochemical, immunohistochemical and ultrastructural techniques. The same immunohistochemical analyses can be performed on cell block specimens. Electron microscopy can easily be performed on cytocentrifuged specimens.

The immunohistochemical features that characterize primary lung adenocarcinomas also characterize pseudomesotheliomatous adenocarcinomas. In addition, the ultrastructural features of pseudomesotheliomatous adenocarcinomas are those of a primary pulmonary adenocarcinoma; namely, a neoplasm that shows short microvilli with prominent glycocalyceal bodies, rootlets, and intracellular or extracellular mucin production. With respect to mucin production, one has to remember that epithelial mesotheliomas can show histochemical staining for PAS-diastase, mucicarmine, and Alcian blue/colloidal iron. Epithelial mesotheliomas that express mucin are usually ones that show extracellular crystalloid structures. The mucin positivity of epithelial mesotheliomas is thought to be related to hyaluronic acid production. It should also be pointed out that primary pulmonary adenocarcinomas and pseudomesotheliomatous adenocarcinomas of the lung can show expression of acidic mucous substances with the colloidal iron and Alcian blue stain that is resistant to hyaluronidase digestion.

Most people in the scientific community who are familiar with pseudomesotheliomatous neoplasms have come to the conclusion that most are made up of cells that form the chest cavity. One issue is where do the cells come from that form the pseudomesotheliomatous lung cancers? The answer to that is not precisely known, although some speculate these neoplasms come from lung tissue that is present in the lung, including bronchi, bronchioles, and alveoli. Some speculate that these cells come from the lung and penetrate through the lung and into the visceral and parietal pleura where they form neoplasms that resemble mesotheliomas, although they are actually formed by epithelioid cells in the lung. Another theory is that some cases of pseudomesotheliomatous lung cancers come from pleural tissue that contains structures such as epithelioid cells and cells that form squamous epithelial cells. In studying pseudomesotheliomatous lung cancers, most 
Hammar et al. Pathology Discovery 2015,

http://www.hoajonline.com/journals/pdf/2052-7896-3-6.pdf

Table 4. Asbestos digestion and fiber analysis results.

\begin{tabular}{|c|c|c|c|c|c|}
\hline Case \# & Age & Sex & Occupation & $\begin{array}{l}\text { Quantitative asbestos digestion analysis } \\
\text { (per gram wet) 5-gram samples except } \\
\text { where noted Performed in Bremerton } \\
\text { laboratory (SPH) }\end{array}$ & $\begin{array}{l}\text { Ferruginous body and uncoated fiber } \\
\text { data per gram dry weight except where } \\
\text { noted Performed in Tyler laboratory } \\
\text { (RFD) }\end{array}$ \\
\hline 002 & $?$ & M & Unknown & $\begin{array}{l}\mathrm{LUL}=50 ; \mathrm{LLL}=70 \\
\mathrm{RUL}=10 ; \mathrm{RML}=50 ; \mathrm{RLL}=10\end{array}$ & Not performed \\
\hline 003 & 67 & M & Millwright & $\begin{array}{l}\mathrm{LUL}=35 ; \mathrm{LLL}=75 \\
\mathrm{RUL}=50 ; \mathrm{RML}=35 ; \mathrm{RLL}=175\end{array}$ & Not performed \\
\hline 008 & 55 & M & $\begin{array}{l}\text { Lived in close proximity to cement plants; } \\
\text { worked for father's pipeline business; } \\
\text { automotive maintenance }\end{array}$ & Not performed & $\begin{array}{l}\text { Left lung } 833 \\
\text { Right lung } 444\end{array}$ \\
\hline 015 & 71 & M & Iron worker & $\begin{array}{l}\mathrm{LUL}=5 ; \mathrm{LLL}=10 \\
\mathrm{RUL}=15 ; \mathrm{RML}=25 ; \mathrm{RLL}=135\end{array}$ & Not performed \\
\hline 026 & 66 & M & Construction worker, pipefitter & 1.5 gram sample lung=55 & Not performed \\
\hline 034 & 57 & M & Unknown & $\begin{array}{l}\text { Sample lung } \# 1=1,500 \\
\text { Sample lung } \# 2=800\end{array}$ & Not performed \\
\hline 041 & 42 & M & Pipefitter, HVAC Tech & Not performed & $\begin{array}{l}\text { Left lung }=32,736 \mathrm{FB} / \text { deparaffinized wet } \\
\text { weight }\end{array}$ \\
\hline 050 & 58 & M & Sheet metal worker & $\begin{array}{l}\mathrm{LUL}=2,600 ; \mathrm{LLL}=1,000 \\
\text { Right lobe } \# 1=1,400 ; \text { Right lobe } \# 2=700\end{array}$ & Not performed \\
\hline 056 & 65 & M & Floor coverer & $\begin{array}{l}\mathrm{LUL}=130 ; \mathrm{LLL}=400 \\
\mathrm{RUL}=105 ; \mathrm{RML}=270 ; \mathrm{RLL}=80\end{array}$ & Not performed \\
\hline 063 & 76 & M & Pipefitter in U.S. Army & $\begin{array}{l}\mathrm{LUL}=320 ; \mathrm{LLL}=135 \\
\mathrm{RUL}=230 ; \mathrm{RML}-65 ; \mathrm{RLL}=70\end{array}$ & Not performed \\
\hline 066 & 77 & M & Plasterer & $\begin{array}{l}\mathrm{LUL}=180 ; \mathrm{LLL}=190 \\
\mathrm{RUL}=45 ; \mathrm{RML}=100 ; \mathrm{RLL}=130\end{array}$ & Not performed \\
\hline 067 & 80 & M & Asbestos worker (? job title) & $\begin{array}{l}\mathrm{LUL}=150 ; \mathrm{LLL}=1,570 \\
\mathrm{RUL}=1,520 ; \mathrm{RML}=375 ; \mathrm{RLL}=1,760\end{array}$ & Not performed \\
\hline 081 & 65 & M & Asbestos brake plant worker & $\begin{array}{l}\mathrm{LUL}=10 ; \mathrm{LLL}=25 \\
\mathrm{RUL}=25 ; \mathrm{RML}=25 ; \mathrm{RLL}=10\end{array}$ & Not performed \\
\hline 088 & 58 & M & Unknown & $\begin{array}{l}\mathrm{LUL}=20 ; \mathrm{LLL}=70 \\
\mathrm{RUL}=10 ; \mathrm{RML}=60 ; \mathrm{RLL}=55 \\
\text { note: there were many more thin uncoated } \\
\text { fibers than there were asbestos bodies, } \\
\text { indicating the concentration of asbestos } \\
\text { was much greater than that suggested by } \\
\text { the asbestos body concentration alone }\end{array}$ & Not performed \\
\hline 089 & 52 & M & Worked at a smelter and refinery & 1.5 gram sample lung $=975$ & Not performed \\
\hline 091 & 55 & M & Automotive mechanic & $\begin{array}{l}\mathrm{LUL}=1,100 ; \mathrm{LLL}=30 \\
\mathrm{RUL}=20 ; \mathrm{RML}=10 ; \mathrm{RLL}=10\end{array}$ & Not performed \\
\hline 092 & 48 & M & $\begin{array}{l}\text { U.S. Army, Assist. VP of merchandising for } \\
\text { drug store }\end{array}$ & $\begin{array}{l}\mathrm{LUL}=<5 ; \mathrm{LLL}=<5 \\
\mathrm{RUL}=15 ; \mathrm{RML}=35 ; \mathrm{RLL}=25\end{array}$ & Not performed \\
\hline 093 & 40 & M & Mechanic, machinist & $\begin{array}{l}\text { Left lung \#1=830; Left lung \#2=2,350 } \\
\text { Right lung \#1=700; Right lung \#2=500 }\end{array}$ & Not performed \\
\hline 095 & 69 & M & Shipyard worker & $\begin{array}{l}\mathrm{LUL}=400 ; \mathrm{LLL}=830 \\
\mathrm{RUL}=830 ; \mathrm{RML}=600 ; \mathrm{RLL}=1,000\end{array}$ & Not performed \\
\hline 096 & 63 & M & Unknown & 1.5 gram sample RLL=2,500 & Not performed \\
\hline 097 & 64 & $\mathrm{M}$ & Unknown & $\begin{array}{l}\mathrm{LUL}=0 ; \mathrm{LLL}=5 \\
\mathrm{RUL}=0 ; \mathrm{RML}=0 ; \mathrm{RLL}=5\end{array}$ & Not performed \\
\hline 098 & 60 & M & Electrician, bricklayer & $\begin{array}{l}\mathrm{LUL}=20 ; \mathrm{LLL}=120 \\
\mathrm{RUL}=230 ; \mathrm{RML}=45 ; \mathrm{RLL}=25\end{array}$ & Not performed \\
\hline 099 & 85 & M & Engineer for government & 2-gram sample $\mathrm{LLL}=30$ & Not performed \\
\hline 110 & 63 & $\mathrm{M}$ & Automobile mechanic & $\begin{array}{l}\text { Left lung \#1 =0; Left lung \#2=0 } \\
\text { RUL = 0; RML=0; RLL=0 }\end{array}$ & Not performed \\
\hline 114 & 54 & M & Unknown & $\begin{array}{l}\mathrm{LUL}=0 ; \mathrm{LLL}=0 \\
\mathrm{RUL}=0 ; \mathrm{RML}=0 ; \mathrm{RLL}=45\end{array}$ & Not performed \\
\hline
\end{tabular}


Hammar et al. Pathology Discovery 2015,

\section{Continuation of Table 4.}

\begin{tabular}{|c|c|c|c|c|c|}
\hline Case \# & Age & Sex & Occupation & $\begin{array}{l}\text { Quantitative asbestos digestion analysis } \\
\text { (per gram wet) 5-gram samples except } \\
\text { where noted Performed in Bremerton } \\
\text { laboratory (SPH) }\end{array}$ & $\begin{array}{l}\text { Ferruginous body and uncoated fiber } \\
\text { data per gram dry weight except where } \\
\text { noted Performed in Tyler laboratory } \\
\text { (RFD) }\end{array}$ \\
\hline 118 & 73 & $\mathrm{M}$ & $\begin{array}{l}\text { Shipyard worker and in U.S. Navy - exposed } \\
\text { to gaskets, packing, refractories, boilers, } \\
\text { pumps, etc. }\end{array}$ & 2-gram sample left lung=785 & Not performed \\
\hline 123 & 66 & M & Marine machinist, railroad brakeman & N/A & $\begin{array}{l}\text { Left lung } 24,290 \\
\text { Right lung } 12,222\end{array}$ \\
\hline 127 & 80 & M & Unknown & $\begin{array}{l}\mathrm{LUL}=9,702 ; \mathrm{LLL}=8,316 \\
\text { RUL=13,100; } \mathrm{RML}=13,900 ; \mathrm{RLL}=13,900\end{array}$ & Not performed \\
\hline 128 & 62 & M & Unknown & $\begin{array}{l}\mathrm{LUL}=400 ; \mathrm{LLL}=265 \\
\mathrm{RUL}=480 ; \mathrm{RML}=345 ; \mathrm{RLL}=130\end{array}$ & Not performed \\
\hline 132 & 60 & M & Mechanic/maintenance man & Lung (lobe not specified) $=100$ & Not performed \\
\hline 133 & 61 & M & Boilerman & $\begin{array}{l}\text { Sample } \# 1=20 \\
\text { Sample } \# 2=<5 \\
\text { Sample } \# 3=15\end{array}$ & Not performed \\
\hline 134 & 74 & M & Unknown & $\begin{array}{l}\mathrm{LUL}=4,850 ; \mathrm{LLL}=2,350 \\
\mathrm{RUL}=2,800 ; \mathrm{RML}=3,600 ; \mathrm{RLL}=3,050\end{array}$ & Not performed \\
\hline 136 & 76 & M & Insulator & $\begin{array}{l}\mathrm{LUL}=9,850 ; \mathrm{LLL}=12,200 \\
\mathrm{RUL}=10,500 ; \mathrm{RML}=5,450 ; \mathrm{RLL}=>25,000\end{array}$ & Not performed \\
\hline 137 & 69 & M & Carpenter/joiner at boatbuilding company & $\begin{array}{l}\mathrm{LUL}=1,535 ; \mathrm{LLL}=1,870 \\
\mathrm{RUL}=3,770 ; \mathrm{RML}=1,200 ; \mathrm{RLL}=1,085\end{array}$ & Not performed \\
\hline 142 & 80 & M & Boilermaker, welder & $\begin{array}{l}\mathrm{LUL}=80 ; \mathrm{LLL}=200 \\
\mathrm{RUL}=1,000 ; \mathrm{RML}=130 ; \mathrm{RLL}=320\end{array}$ & Not performed \\
\hline 146 & 70 & M & Insulator helper ( 5 years) & $\begin{array}{l}\mathrm{LUL}=4,330 ; \mathrm{LLL}=6,250 \\
\mathrm{RUL}=6,300 ; \mathrm{RML}=5,755 ; \mathrm{RLL}=12,235\end{array}$ & $\begin{array}{l}\text { Left lung } 3,565,000 \\
\text { Right lung } 12,685,000\end{array}$ \\
\hline 147 & 74 & M & Shipyard worker (29 years) & $\begin{array}{l}\mathrm{LUL}=120 ; \mathrm{LLL}=680 \\
\mathrm{RUL}=225 ; \mathrm{RML}=185 ; \mathrm{RLL}=375\end{array}$ & $\begin{array}{l}\text { Left lung 7,078,000 } \\
\text { Right lung } 1,190,000\end{array}$ \\
\hline 148 & 75 & M & $\begin{array}{l}\text { Shipfitter, chipper, caulker, nuclear test } \\
\text { director }\end{array}$ & $\begin{array}{l}\mathrm{LUL}=1,750 ; \mathrm{LLL}=3,320 \\
\mathrm{RUL}=1,100 ; \mathrm{RML}=250 ; \mathrm{RLL}=875\end{array}$ & $\begin{array}{l}\text { Left lung } 461,000 \\
\text { Right lung } 4,265,000\end{array}$ \\
\hline 149 & 75 & M & Shipyard electrician & $\begin{array}{l}\mathrm{LUL}=1,655 ; \mathrm{LLL}=1,285 \\
\mathrm{RUL}=3,235 ; \mathrm{RML}=1,875 ; \mathrm{RLL}=6,250\end{array}$ & $\begin{array}{l}\text { Left lung } 1,136,000 \\
\text { Right lung 2,862,000 }\end{array}$ \\
\hline 150 & 76 & M & Built kitchen equipment & $\begin{array}{l}\mathrm{LUL}=130 ; \mathrm{LLL}=10 \\
\mathrm{RUL}=125 ; \mathrm{RML}=320 ; \mathrm{RLL}=305\end{array}$ & $\begin{array}{l}\text { Left lung } 1,588,000 \\
\text { Right lung } 726,000\end{array}$ \\
\hline 151 & 43 & M & $\begin{array}{l}\text { Batchmaker, mixer, hod carrier, pipelayer, } \\
\text { laborer, maintenance man }\end{array}$ & $\begin{array}{l}\mathrm{LUL}=260 ; \mathrm{LLL}=40 \\
\mathrm{RUL}=60 ; \mathrm{RML}=60 ; \mathrm{RLL}=250\end{array}$ & $\begin{array}{l}\text { Left lung } 1,128,000 \\
\text { Right lung } 1,400,000\end{array}$ \\
\hline 152 & 69 & M & Steamfitter and plumber ( 25 years) & $\begin{array}{l}\mathrm{LUL}=320 ; \mathrm{LLL}=250 \\
\mathrm{RUL}=230 ; \mathrm{RML}=580 ; \mathrm{RLL}=400\end{array}$ & $\begin{array}{l}\text { Left lung } 1,297,000 \\
\text { Right lung } 1,160,000\end{array}$ \\
\hline 153 & 61 & M & Electrician (20 years) & $\begin{array}{l}\mathrm{LUL}=532 ; \mathrm{LLL}=20 \\
\text { RUL=25; RML }=185 ; \mathrm{RLL}=150\end{array}$ & $\begin{array}{l}\text { Left lung } 294,000 \\
\text { Right lung } 1,004,000\end{array}$ \\
\hline 154 & 71 & M & $\begin{array}{l}\text { Wiper \& oiler ( } 3 \text { years); insulator \& pipefit- } \\
\text { ter ( } 35 \text { years) }\end{array}$ & $\begin{array}{l}\text { LUL }=860 ; \mathrm{LLL}=3,460 \\
\text { RUL, RML \& RLL=unable to evaluate }\end{array}$ & $\begin{array}{l}\text { Left lung 748,000 } \\
\text { Right lung 704,000 }\end{array}$ \\
\hline 155 & 62 & M & Electrician ( 45 years) & $\begin{array}{l}\text { Sample } \# 1=80 \\
\text { Sample } \# 2=210\end{array}$ & $\begin{array}{l}\text { Left lung } 392,000 \\
\text { Right lung } 453,000\end{array}$ \\
\hline 156 & $?$ & M & Unknown & $\begin{array}{l}\text { Left lung \#1=80; Left lung } \# 2=300 \\
\text { RUL=2,000; RML=1,450; RLL=2,010 }\end{array}$ & $\begin{array}{l}\text { Left lung } 253,000 \\
\text { Right lung } 348,000\end{array}$ \\
\hline 157 & 64 & M & $\begin{array}{l}\text { Shipyard insulator \& shipwright ( } 5 \text { years); } \\
\text { lineman }\end{array}$ & $\begin{array}{l}\mathrm{LUL}=135 ; \mathrm{LLL}=85 \\
\mathrm{RUL}=580 ; \mathrm{RML}=30 ; \mathrm{RLL}=30\end{array}$ & $\begin{array}{l}\text { Left lung } 324,000 \\
\text { Right lung } 327,000\end{array}$ \\
\hline 158 & $?$ & M & Unknown & $\begin{array}{l}\text { Left lung } \# 1=20 \text {; Left lung } \# 2=45 \\
\text { RUL= } 45 ; \text { RML= } 75 ; \text { RLL=165 }\end{array}$ & $\begin{array}{l}\text { Left lung - not evaluated } \\
\text { Right lung } 292,000\end{array}$ \\
\hline 159 & 59 & M & $\begin{array}{l}\text { Shipyard sandblaster \& painter ( } 13 \text { years); } \\
\text { head hooker and furnace manager at a steel } \\
\text { plant (18 years); laborer }\end{array}$ & $\begin{array}{l}\mathrm{LUL}=10 ; \mathrm{LLL}=10 \\
\mathrm{RUL}=10 ; \mathrm{RML}=15 ; \mathrm{RLL}=65\end{array}$ & $\begin{array}{l}\text { Left lung 206,000 } \\
\text { Right lung 257,000 }\end{array}$ \\
\hline 160 & 67 & M & $\begin{array}{l}\text { Shipyard worker ( } 3 \text { years); boatswains mate } \\
\text { (9 years) }\end{array}$ & $\begin{array}{l}\mathrm{LUL}=0 ; \mathrm{LLL}=0 \\
\mathrm{RUL}=0 ; \mathrm{RML}=20 ; \mathrm{RLL}=20\end{array}$ & $\begin{array}{l}\text { Left lung } 25,000 \\
\text { Right lung } 192,000\end{array}$ \\
\hline 161 & $?$ & M & Unknown & Not performed & $\begin{array}{l}\text { Left lung } 183,000 \\
\text { Right lung } 25,000\end{array}$ \\
\hline
\end{tabular}


Hammar et al. Pathology Discovery 2015,

Continuation of Table 4 .

\begin{tabular}{|c|c|c|c|c|c|}
\hline Case \# & Age & Sex & Occupation & $\begin{array}{l}\text { Quantitative asbestos digestion analysis } \\
\text { (per gram wet) 5-gram samples except } \\
\text { where noted Performed in Bremerton } \\
\text { laboratory (SPH) }\end{array}$ & $\begin{array}{l}\text { Ferruginous body and uncoated fiber } \\
\text { data per gram dry weight except where } \\
\text { noted Performed in Tyler laboratory } \\
\text { (RFD) }\end{array}$ \\
\hline 162 & 77 & $\mathrm{M}$ & Unknown & $\begin{array}{l}\mathrm{LUL}=<5 ; \mathrm{LLL}=20 \\
\mathrm{RUL}=15 ; \mathrm{RML}=10 ; \mathrm{RLL}=85\end{array}$ & $\begin{array}{l}\text { Left lung 58,000 } \\
\text { Right lung } 174,000\end{array}$ \\
\hline 163 & 62 & M & Unknown & $\begin{array}{l}\mathrm{LUL}=0 ; \mathrm{LLL}=0 \\
\mathrm{RUL}=<1 ; \mathrm{RML}=<1 ; \mathrm{RLL}=<1\end{array}$ & $\begin{array}{l}\text { Left lung - none detected } \\
\text { Right lung } 87,000\end{array}$ \\
\hline 164 & 64 & M & Unknown & $\begin{array}{l}\mathrm{LUL}=0 ; \mathrm{LLL}=5 \\
\mathrm{RUL}=0 ; \mathrm{RML}=0 ; \mathrm{RLL}=5\end{array}$ & $\begin{array}{l}\text { Left lung } 69,000 \\
\text { Right lung - none detected }\end{array}$ \\
\hline 165 & 53 & M & Laborer, carpenter, service station manager & $\begin{array}{l}\mathrm{LUL}=0 ; \mathrm{LLL}=<1 \\
\mathrm{RUL}=3 ; \mathrm{RML}=<1 ; \mathrm{RLL}=<1\end{array}$ & $\begin{array}{l}\text { Left lung } 54,000 \\
\text { Right lung } 25,000\end{array}$ \\
\hline 166 & 96 & M & Boilermaker & $\begin{array}{l}\mathrm{LUL}=1,675 ; \mathrm{LLL}=750 \\
\mathrm{RUL}=2,340 ; \mathrm{RML}=3,485 ; \mathrm{RLL}=4,950\end{array}$ & Not performed \\
\hline 173 & 68 & M & Driller in shipyard & $\begin{array}{l}\mathrm{LUL}=75 ; \mathrm{LLL}=55 \\
\mathrm{RUL}=25 ; \mathrm{RML}=0 ; \mathrm{RLL}=65\end{array}$ & Not performed \\
\hline 189 & 67 & M & Sheet metal worker & $\begin{array}{l}\mathrm{LUL}=250 ; \mathrm{LLL}=135 \\
\mathrm{RUL}=30 ; \mathrm{RML}=30 ; \mathrm{RLL}=40\end{array}$ & Not performed \\
\hline 194 & 84 & M & Mechanic, welder & Not performed & $\begin{array}{l}123 \mathrm{FB} \text { equivalent to } 2,472.51 \mathrm{AF} / \mathrm{gram} \\
\text { deparaffinized wet weight }\end{array}$ \\
\hline
\end{tabular}

Key: AF: Asbestos fibers; FB: Ferruginous bodies; LL: Left lung; LUL: Left upper lobe; LLL: Left lower lobe; RL: Right lung; RUL: Right upper lobe; RML: Right middle lobe; RLL: Right lower lobe; M: Male; F: Female; ?: unknown

come to the conclusion based on the evidence available that the majority of pseudomesotheliomatous lung cancers are adenocarcinomas that directly invade the pleura and many are associated with a marked desmoplastic reaction.

There is some controversy as to whether scarring causes the cancer or whether the scarring already existed, such as scarring from tuberculosis or some other type of inflammatory condition. At this point in time, most scientists would state that, in most instances, the scarring that is associated with pseudomesotheliomatous lung cancers is not pre-existing but is actually caused by the tumor itself. That is also the case with most cancers; e.g., it is thought that the scarring in breast cancer is caused by the tumor and not by some pre-existing condition.

\section{Conclusion}

As shown in our case series, there appears to be a causal/ historical link between persons exposed to asbestos and the development of pseudomesotheliomatous lung carcinomas, just as there is a link between asbestos and primary pulmonary carcinomas, mesothelioma, and other asbestos-related cancers. We conclude that when we evaluated asbestos as a potential cause in these cases of pseudomesotheliomatous neoplasms, correlation with asbestos-related changes or actual presence of biological markers of past exposure indicated a link between the development of this unique tumor and exposure to asbestos in most cases within the study. In the case of pseudomesotheliomatous lung carcinomas, there also appears to be a causal link to cigarette smoking in that 109 patients (55\%) had a known history of cigarette smoking, although in 64 cases the smoking history was unknown. This causal relationship is not surprising in that most cases were primary pulmonary adenocarcinomas, which is a recognized cancer caused by cigarette smoke carcinogens. Furthermore, the combination of asbestos exposure and smoking is recognized to result in a synergistic effect on the risk for development of a lung cancer.

\section{Competing interests}

The authors declare that they have no competing interests.

\section{Authors' contributions}

\begin{tabular}{|l|c|c|}
\hline Authors' contributions & SPH & RFD \\
\hline Research concept and design & $\checkmark$ & $\checkmark$ \\
\hline Collection and/or assembly of data & $\checkmark$ & -- \\
\hline Data analysis and interpretation & $\checkmark$ & -- \\
\hline Writing the article & $\checkmark$ & $\checkmark$ \\
\hline Critical revision of the article & $\checkmark$ & $\checkmark$ \\
\hline Final approval of article & $\checkmark$ & $\checkmark$ \\
\hline Statistical analysis & $\checkmark$ & $\checkmark$ \\
\hline
\end{tabular}

Acknowledgement

We wish to thank Michaele Stoll for her editorial and research skills, which enabled us to finalize the complex data presented in this manuscript. We also wish to thank Teresa Bair and Hector Hallman for their assistance.

Publication history

Editor: Jae Y. Ro, Houston Methodist Hospital, USA. EIC: Markus H. Frank, Harvard Medical School, USA. Received: 04-Jun-2015 Final Revised: 24-Jul-2015 Accepted: 14-Aug-2015 Published: 25-Aug-2015

\section{References}

1. Babolini $G$ and Blasi $A$. The pleural form of primary cancer of the lung. Dis Chest. 1956; 29:314-23. I Article I PubMed

2. Harwood TR, Gracey DR and Yokoo H. Pseudomesotheliomatous 
Hammar et al. Pathology Discovery 2015,

carcinoma of the lung. A variant of peripheral lung cancer. Am J Clin Pathol. 1976; 65:159-67. | Article | PubMed

3. Braganza JM, Butler EB, Fox H, Hunter PM, Qureshi MS, Samarji W and Vallon AG. Ectopic production of salivary type amylase by a pseudomesotheliomatous carcinoma of the lung. Cancer. 1978; 41:1522-5. | Pdf | PubMed

4. Broghamer WL, Jr., Collins WM and Mojsejenko IK. The cytohistopathology of a pseudomesotheliomatous carcinoma of the lung. Acta Cytol. 1978; 22:239-42. I Article I PubMed

5. Lin Jl, Tseng $\mathrm{CH}$ and Tsung SH. Pseudomesotheliomatous carcinoma of the lung. South Med J. 1980; 73:655-7. I Article I PubMed

6. Nishimoto $Y$, Ohno T and Saito K. Pseudomesotheliomatous carcinoma of the lung with histochemical and immunohistochemical study. Acta Pathol Jpn. 1983; 33:415-23. | Article | PubMed

7. Simonsen J. Pseudomesotheliomatous carcinoma of the lung with asbestos exposure. Am J Forensic Med Pathol. 1986; 7:49-51. | Article | PubMed

8. Dessy E and Pietra GG. Pseudomesotheliomatous carcinoma of the lung. An immunohistochemical and ultrastructural study of three cases. Cancer. 1991; 68:1747-53. | Article | PubMed

9. Huncharek $M$ and Muscat J. Metastatic laryngeal carcinoma mimicking pleural mesothelioma. Respiration. 1991; 58:204-6. | Article | PubMed

10. Koss M, Travis W, Moran C and Hochholzer L. Pseudomesotheliomatous adenocarcinoma: a reappraisal. Semin Diagn Pathol. 1992; 9:117-23. | PubMed

11. Robb JA, Hammar SP and Yooko H. Pseudomesotheliomatous lung carcinoma: a rare asbestos-related malignancy readily separable from epithelial pleural mesothelioma. Lab Invest. 1993; 68:134A.

12. Hartmann CA and Schutze H. Mesothelioma-like tumors of the pleura: a review of 72 autopsy cases. J Cancer Res Clin Oncol. 1994; 120:331-47. I Article | PubMed

13. Brunner-La Rocca HP, Schlossberg D and Vogt P. [Pseudomesotheliomatous carcinoma in HIV infection]. Dtsch Med Wochenschr. 1995; 120:1312-7. | Article | PubMed

14. Falconieri G, Zanconati F, Bussani R and Di Bonito L. Small cell carcinoma of lung simulating pleural mesothelioma. Report of 4 cases with autopsy confirmation. Pathol Res Pract. 1995; 191:1147-52. | Article | PubMed

15. Lin BT, Colby T, Gown AM, Hammar SP, Mertens RB, Churg A and Battifora $\mathrm{H}$. Malignant vascular tumors of the serous membranes mimicking mesothelioma. A report of 14 cases. Am J Surg Pathol. 1996; 20:1431-9. | Article | PubMed

16. Koss MN, Fleming M, Przygodzki RM, Sherrod A, Travis W and Hochholzer L. Adenocarcinoma simulating mesothelioma: a clinicopathologic and immunohistochemical study of 29 cases. Ann Diagn Pathol. 1998; 2:93102. | Article | PubMed

17. Shah IA, Salvatore JR, Kummet T, Gani OS and Wheeler LA. Pseudomesotheliomatous carcinoma involving pleura and peritoneum: A clinicopathologic and immunohistochemical study of three cases. Ann Diagn Pathol. 1999; 3:148-59. | Article | PubMed

18. Zhang PJ, Livolsi VA and Brooks JJ. Malignant epithelioid vascular tumors of the pleura: report of a series and literature review. Hum Pathol. 2000; 31:29-34. | Article | PubMed

19. Attanoos RL, Suvarna SK, Rhead E, Stephens M, Locke TJ, Sheppard MN, Pooley FD and Gibbs AR. Malignant vascular tumours of the pleura in "asbestos" workers and endothelial differentiation in malignant mesothelioma. Thorax. 2000; 55:860-3. | Article | PubMed Abstract | PubMed Full Text

20. Tang $P$, Vatsia SK, Teichberg $S$ and Kahn E. Pulmonary adenocarcinoma simulating malignant mesothelioma. Arch Pathol Lab Med. 2001; 125:1598-600. | Article | PubMed

21. van Hengel P, van Geffen F, Kazzaz BA and Heyerman HG. Atypical carcinoid presenting as mesothelioma. Neth J Med. 2001; 58:185-90. | Article | PubMed

22. Vaideeswar P, Deshpande JR and Jambhekar NA. Primary pleuropulmonary malignant germ cell tumours. J Postgrad Med. 2002; 48:29-

\section{1. | Article | PubMed}

23. Del Frate C, Mortele K, Zanardi R, Hunsaker AR, Nikpoor N, Cibas ES and Silverman SG. Pseudomesotheliomatous angiosarcoma of the chest wall and pleura. J Thorac Imaging. 2003; 18:200-3. | Article | PubMed

24. Attanoos RL and Gibbs AR. 'Pseudomesotheliomatous' carcinomas of the pleura: a 10-year analysis of cases from the Environmental Lung Disease Research Group, Cardiff. Histopathology. 2003; 43:444-52. | Article | PubMed

25. Ando S, Kimura H, Iwai N, Yamamoto $\mathrm{N}$ and lida T. [An autopsy case of pseudomesotheliomatous adenocarcinoma of the lung complicated with brain stem infarction due to nonbacterial thrombotic endocarditis]. Nihon Kokyuki Gakkai Zasshi. 2003; 41:728-32. | Article | PubMed

26. Guru PK, Phillips S, Ball MM, Das A and Singh S. Pseudomesotheliomatous presentation of primary signet ring cell carcinoma of lung. Indian J Chest Dis Allied Sci. 2005; 47:209-11. | Article I PubMed

27. Kobashi Y, Matsushima T and Irei T. Clinicopathological analysis of lung cancer resembling malignant pleural mesothelioma. Respirology. 2005; 10:660-5. | Article | PubMed

28. Ulubay G, Eyuboglu FO, Simsek A and Ozyilkan O. Multiple myeloma with pleural involvement: a case report. Am J Clin Oncol. 2005; 28:429-30. I Article I PubMed

29. Luckraz H, Morgan M, Gibbs AR and Butchart EG. Pseudomesothelioma resulting from metastatic malignant melanoma. Eur J Cardiothorac Surg. 2005; 28:655-6. | Article | PubMed

30. Yoshimi R, Takeno M, Yamanaka S, Shiina M, Kirino Y, Takeda Y, Sekiguchi A, Kobayashi H, Ihata A, Motoji K, Ohno S, Ueda A, Soga T and Ishigatsubo $Y$. Systemic sclerosis and pseudomesotheliomatous adenocarcinoma of the lung. Mod Rheumatol. 2006; 16:165-8. | Article | PubMed

31. Saboerali MD, Koolen MG, Noorduyn LA, van Delden OM and Bogaard $\mathrm{HJ}$. Pleural thickening in a construction worker: it is not always mesothelioma. Neth J Med. 2006; 64:88-90. | Pdf | PubMed

32. Kaira K, Sunaga N, Yanagitani N, Hisada T, Ishizuka T and Mori M. Pseudomesotheliomatous adenocarcinoma of the lung with synchronous gastric and esophageal cancer. Australas Radiol. 2007; 51 Suppl:B265-7. | Article | PubMed

33. Pardo J, Torres W, Martinez-Penuela A, Panizo A, de Alava E and Garcia $\mathrm{JL}$. Pseudomesotheliomatous carcinoma of the lung with a distinct morphology, immunohistochemistry, and comparative genomic hybridization profile. Ann Diagn Pathol. 2007; 11:241-51. | Article | PubMed

34. Maeda R, Isowa N, Kawasaki Y, Tokuyasu H, Itakura A, Miura H and Onuma H. [Pseudomesotheliomatous carcinoma of the lung]. Kyobu Geka. 2007; 60:555-8. | Article | PubMed

35. Colonna A, Gualco G, Bacchi CE, Leite MA, Rocco M, DeMaglio G, Pizzolitto $S$ and Falconieri G. Plasma cell myeloma presenting with diffuse pleural involvement: a hitherto unreported pattern of a new mesothelioma mimicker. Ann Diagn Pathol. 2010; 14:30-5. | Article | PubMed

36. Takeuchi T, Iwasaki S, Miyazaki J, Nozaki Y, Takahashi M, Ono M, Saibara $T$ and Furihata M. Matrix metalloproteinase-1 expression in splenic angiosarcoma metastasizing to the serous membrane. Int J Clin Exp Pathol. 2010; 3:634-9. | PubMed Abstract | PubMed Full Text

37. Snaebjornsson P, Vos CG, Hartemink KJ, Lely RJ, Samii SM, Grunberg K and Paul MA. Fatal hemothorax caused by pseudomesotheliomatous carcinoma of the lung. Patholog Res Int. 2011; 2011:836054. | Article | PubMed Abstract I PubMed Full Text

38. Leopold GD and Attanoos RL. The importance of retaining post mortem tissue--'pseudomesotheliomatous' Merkel cell carcinoma of the pleura. Histopathology. 2011; 58:1180-2. | Article | PubMed

39. Nakamori T, Kosuda S, Kyoto Y, Fujikawa A, Naoi Y and Nakamori Y. Pseudomesotheliomatous lung cancer mimicking mesothelioma on (1) (8)F-FDG PET/CT images: report of 2 cases. Jpn J Radiol. 2013; 31:542-5. | Article | PubMed

40. Kassir $R$, Forest $F$ and Kaczmarek D. Pulmonary mucinous 
Hammar et al. Pathology Discovery 2015,

http://www.hoajonline.com/journals/pdf/2052-7896-3-6.pdf

cystadenocarcinoma presenting as a pleural mesothelioma. Int I Surg

Case Rep. 2013; 4:942-4. | Article | PubMed Abstract | PubMed Full Text

41. Dodson RF, Williams MG, Huang J and Bruce JR. Tissue burden of asbestos in nonoccupationally exposed individuals from east Texas. $\mathrm{Am}$ J Ind Med. 1999; 35:281-6. | Article | PubMed

42. Williams MG, Jr., Dodson RF, Corn C and Hurst GA. A procedure for the isolation of amosite asbestos and ferruginous bodies from lung tissue and sputum. J Toxicol Environ Health. 1982; 10:627-38. | Article | PubMed

43. Dodson RF and Hammar SP. Analysis of asbestos concentration in $\mathbf{2 0}$ cases of pseudomesotheliomatous lung cancer. Ultrastruct Pathol. 2015; 39:13-22. | Article | PubMed

44. Jaffe MS. Handling and washing fragile replicas. Proc Electron Microscope Society of America, Toronto. J Appl Phys. 1948; 19:1187.

45. Dodson RF, O'Sullivan MF, Brooks DR and Bruce JR. Asbestos content of omentum and mesentery in nonoccupationally exposed individuals. Toxicol Ind Health. 2001; 17:138-43. | Article | PubMed

Citation:

Hammar SP and Dodson RF. Pseudomesotheliomatous lung carcinoma: a pathological assessment of selected cases including the work history and presence of biomarkers suggesting it is a cancer caused by asbestos. Pathol Discov. 2015; 3:6.

http://dx.doi.org/10.7243/2052-7896-3-6 